\title{
Voltages Induced on an Overhead Wire by Lightning Strikes to a Nearby Tall Grounded Object
}

\author{
Yoshihiro Baba, Member, IEEE, and Vladimir A. Rakov, Fellow, IEEE
}

\begin{abstract}
The aim of this study was to identify conditions under which the presence of tall strike object can serve to increase or decrease lightning-induced voltages on a nearby overhead wire. We examined the ratios of magnitudes of lightning-induced voltages on the overhead wire for the cases of strikes to a tall object and to flat ground as a function of distance from the lightning channel $d$, current reflection coefficients at the top of the strike object $\rho_{\text {top }}$ and at the bottom of the strike object $\rho_{\text {bot }}$, the current reflection coefficient at the channel base (in the case of strikes to flat ground) $\rho_{\mathrm{gr}}$, and the return stroke speed $v$. Lightning-induced voltages were computed using the finite-difference time-domain (FDTD) method. The transmission line (TL) model was used to find the distribution of current along the lightning channel and the strike object. The ratio of magnitudes of lightning-induced voltages for tall-object and flat-ground cases increases with increasing $d$ (ranging from 40-200 m), decreasing $\rho_{\text {bot }}(<1)$, decreasing $\rho_{\text {top }}(<0$, except for the case of $\left.\rho_{\text {bot }}=0\right)$, and decreasing $v(<c$, speed of light $)$. Also, the ratio increases with decreasing the lightning current rise time. Under realistic (expected) conditions such as $\rho_{\text {bot }}=1, \rho_{\text {top }}=-0.5$, and $v=c / 3$, the ratio is larger than unity (the tall strike object serves to enhance lightning-induced voltages), but it becomes smaller than unity (the tall object serves to decrease lightning-induced voltages) under some special conditions, such as $\rho_{\text {bot }}=1, \rho_{\text {top }}=0$, and $v=c$.
\end{abstract}

Index Terms-FDTD method, lightning, lightning-induced voltage, return stroke model, tall object, transmission line (TL) model.

\section{INTRODUCTION}

$\mathbf{I}$ $\mathrm{N}$ ORDER to optimize lightning protection means of telecommunication and power distribution lines, one needs to know voltages that can be induced on overhead wires by lightning strikes to ground or to nearby grounded objects. It appears that the presence of tall strike object can serve to either increase or decrease lightning electric fields and lightning-induced voltages, as discussed in this paper.

Fisher and Schnetzer [1] examined the dependence of triggered-lightning electric fields on the height of strike object at Fort McClellan, AL. The fields were measured at distances of 9.3 and $19.3 \mathrm{~m}$ from the base of a metallic strike rod whose height was either 4.5 or $11 \mathrm{~m}$. They observed that the leader electric fields (approximately equal in magnitude to their corresponding return stroke fields at such close distances) tended to be reduced as the height of the strike object increased. Thus, it appears that the presence of a strike object served to reduce

Manuscript received March 11, 2005; revised October 10, 2005. This work was supported in part by Doshisha University and by NSF grant ATM-0346164.

Y. Baba is with the Department of Electrical Engineering, Doshisha University, Kyoto 6100321, Japan (e-mail: ybaba@mail.doshisha.ac.jp).

V. A. Rakov is with the Department of Electrical and Computer Engineering, University of Florida, Gainesville, FL 32611 USA (e-mail: rakov@ece.ufl.edu). Digital Object Identifier 10.1109/TEMC.2006.870807 electric fields in its vicinity relative to the case of lightning strike to flat ground.

Miyazaki and Ishii [2], using the Numerical Electromagnetic Code (NEC-2) [3], examined the influence of the presence of a tall strike object (60-240 $\mathrm{m}$ in height) on the associated electromagnetic fields at ground level $100 \mathrm{~m}$ to $500 \mathrm{~km}$ away from the base of the strike object. They represented the lightning channel by a vertical wire having distributed resistance $(1 \Omega / \mathrm{m})$ and additional distributed inductance $(3 \mu \mathrm{H} / \mathrm{m})$, energized by a voltage source connected between the channel and the strike object represented by a vertical perfectly conducting wire. The voltage source had an internal resistance of $300 \Omega$. Grounding resistance of the strike object was assumed to be $30 \Omega$, and the ground conductivity was set to $0.003 \mathrm{~S} / \mathrm{m}$. The ratio of the calculated vertical electric field due to a lightning strike to the tall object versus that due to the same strike to flat ground was found to be smaller than unity at horizontal distances of 100-600 $\mathrm{m}$ from the lightning channel and larger than unity at distances beyond $600 \mathrm{~m}$. The ratio reached its peak around several kilometers from the channel and then exhibited a decrease with increasing horizontal distance. Miyazaki and Ishii noted that the latter decrease was due to the propagation effects (preferential attenuation of higher frequency components of the electromagnetic wave as it propagates over lossy ground).

Baba and Rakov [4] compared the distance dependences of vertical electric and azimuthal magnetic fields due to a lightning strike to a tall object with those due to the same strike to flat ground, using the transmission line (TL) model extended to include a tall strike object [5]. In this model, any grounding impedance can be directly specified, and the total charge transfer to ground is the same regardless of the presence of the strike object. Their findings can be summarized as follows: The electric field for the strike-object case is reduced relative to the flat-ground case at closer distances from the object. In an idealized case that is characterized by the return stroke front speed equal to the speed of light $v=c$, the current reflection coefficient at the bottom of the strike object $\rho_{\text {bot }}=1$ (grounding impedance $Z_{\mathrm{gr}}=0$ ), and that at the top of the object for upward-propagating waves $\rho_{\text {top }}=0$ (characteristic impedance of the object is equal to that of the channel $Z_{\mathrm{ob}}=Z_{\mathrm{ch}}$ ), the ratio of the vertical electric fields at ground level for the strikeobject and flat-ground cases (electric field attenuation factor) is $d / \sqrt{ }\left(d^{2}+h^{2}\right)$, where $h$ is the height of the strike object, and $d$ is the horizontal distance from the object. The corresponding ratio for the azimuthal magnetic field is equal to unity. Baba and Rakov [4] showed that the ratio for either electric or magnetic field increased with decreasing $\rho_{\text {bot }}\left(\rho_{\text {bot }}<1\right)$, decreasing 
$\rho_{\text {top }}\left(\rho_{\text {top }}<0\right.$, except for the case of $\left.\rho_{\text {bot }}=0\right)$, and decreasing $v(v<c)$, and that at larger distances, it became greater than unity.

It follows from the above that the presence of a tall strike object reduces lightning electric fields relative to the case of strikes to flat ground at closer ranges and enhances them at larger distances. Note that the enhancement of remote lightning electric and magnetic fields by the presence of a tall strike object was also discussed by Diendorfer and Schulz [6], Rachidi et al. [7], Rakov [8], Kordi et al. [9], and Bermudez et al. [10].

Piantini and Janiszewski [11] have shown that the magnitude of lightning-induced voltage at the center point of a 5-km-long horizontal wire matched at each end and located $10 \mathrm{~m}$ above perfectly conducting ground and $50 \mathrm{~m}$ away from the strike object increases with increasing the height of the object from 0 to $150 \mathrm{~m}$ if the rise time (RT) of the lightning current is $0.5 \mu \mathrm{s}$ and decreases if the RT is $1 \mu \mathrm{s}$ or longer. Piantini and Janiszewski [12] have also shown that the magnitude of lightning-induced voltage, at the center point of a $10-\mathrm{km}$-long horizontal wire located $10 \mathrm{~m}$ above perfectly conducting ground and $60 \mathrm{~m}$ away from the vertical lightning channel, decreases as the height of the junction point of the descending and upward connecting leaders gets larger when the RT of the lightning current is $3 \mu \mathrm{s}$. (Note that an upward connecting leader launched from flat ground can be regarded as a tall grounded strike object.) They assumed that the current reflection coefficient at the bottom of the strike object [11] or at the bottom of the upward connecting leader [12] was equal to zero. Induced voltages were computed using the Rusck model [13] of field-to-wire electromagnetic coupling extended to include a tall strike object and assuming that the current propagation speeds along the vertical lightning channel and along the strike object were $0.3 c$ and $c$, respectively. Note that Cooray [14] showed that the Rusck model was incomplete (because it neglected the portion of the horizontal electric field due to the vector potential) but yielded induced voltages that were identical to those calculated using the more accurate Agrawal model [15] for the case of an infinitely long horizontal wire and a vertical lightning strike to flat perfectly conducting ground. Further, Michishita and Ishii [16] showed that the Rusck model was equivalent to the Agrawal model even if the horizontal wire had a finite length. Piantini and Janiszewski [11] demonstrated that the validity of the Rusck model extended to include a strike object by comparing calculated voltages with those measured in experiments of Yokoyama et al. [17], [18]. Note that in the Agrawal model, the sources are expressed in terms of electric excitation field. Rachidi [19] derived an equivalent model in which the sources are expressed solely in terms of magnetic excitation field.

Silveira and Visacro [20] (see also [21]) have shown that the magnitude of lightning-induced voltage on a 300-m-long horizontal wire matched at each end that was located $10 \mathrm{~m}$ above perfectly conducting ground and $100 \mathrm{~m}$ away from the vertical lightning channel increases with increasing the height of the junction point between the descending and upward connecting leaders. They employed a model based on the hybrid electromagnetic field/circuit theory approach [22], in which the current
TABLE I

RELATIONS BETWEEN CURRENT REFLECTION COEFFICIENTS $\left(\rho_{\text {top }}, \rho_{\text {bot }}\right.$, AND $\left.\rho_{\text {gr }}\right)$ AND IMPEDANCES $\left(Z_{\mathrm{ob}}, Z_{\mathrm{ch}}\right.$, AND $\left.Z_{\mathrm{gr}}\right)$ FOR FOUR DIFFERENT SETS OF $\rho_{\text {top }}$ AND $\rho_{\text {bot }}$

\begin{tabular}{c|c|c|c}
\hline$\rho_{t o p}$ & $\rho_{b o t}$ & Impedances from equations (1a) and (1b) & $\rho_{g r}$ \\
\hline-0.5 & 1 & $Z_{g r}=0, \quad Z_{o b}=Z_{c h} / 3$ & 1 \\
0 & 1 & $Z_{g r}=0, \quad Z_{o b}=Z_{c h}$ & 1 \\
-0.5 & 0 & $Z_{g r}=Z_{o b}, Z_{o b}=Z_{c h} / 3$ & 0.5 \\
0 & 0 & $Z_{g r}=Z_{o b}=Z_{c h}$ & 0 \\
\hline
\end{tabular}

Note that $\rho_{b o t}=1$ can be also achieved when $Z_{g y} \ll<Z_{o b}$ (as opposed to $Z_{g y}=0$ ). Also note that, in the case of $\rho_{b o t}=0\left(Z_{g r}=Z_{o b}\right), \rho_{g r}$ becomes equal to - $\rho_{t o p}$. Thus, the magnitude of current waves injected into both the lightning channel and the strike object in the case of strike to tall object, $\left(1-\rho_{s o p}\right) I_{s c} / 2$, becomes equal to that injected into the channel in the case of the same strike to flat ground, $\left(1+\rho_{g r}\right) I_{s c} / 2$.

wave propagation speed along the leader channels both above and below the junction point was equal to $c$ and used a current waveform having a RT of $1 \mu \mathrm{s}$.

Voltages induced by lightning strikes to a tall object were also calculated by Michishita et al. [23], who represented the strike object by an R-L-C distributed circuit (R, L, and C stand for resistance, inductance, and capacitance, respectively) and used the Agrawal model, and by Pokharel et al. [24], who represented the strike object by a vertical perfectly conducting wire and used NEC-2. Both groups employed Norton's approximation [25] to take into account the lossy-ground effect and succeeded in reproducing the corresponding measured voltages induced by lightning strikes to a 200-m-high object (Fukui chimney).

In this paper, we examine the ratios of magnitudes of lightning-induced voltages for the cases of strikes to a tall object and to flat ground as a function of distance from the lightning channel $d$, height of the strike object $h$, the current reflection coefficients at the extremities of the strike object $\rho_{\text {top }}$ and $\rho_{\text {bot }}$, the current reflection coefficient at the channel base (ground) in the case of strikes to flat ground $\rho_{\mathrm{gr}}$, the RT of lightning return stroke current, and the return stroke speed $v$. The reflection coefficients $\rho_{\text {top }}, \rho_{\text {bot }}$, and $\rho_{\text {gr }}$ are given by

$$
\begin{gathered}
\rho_{\mathrm{top}}=\frac{Z_{\mathrm{ob}}-Z_{\mathrm{ch}}}{Z_{\mathrm{ob}}+Z_{\mathrm{ch}}} \\
\rho_{\mathrm{bot}}=\frac{Z_{\mathrm{ob}}-Z_{\mathrm{gr}}}{Z_{\mathrm{ob}}+Z_{\mathrm{gr}}} \\
\rho_{\mathrm{gr}}=\frac{Z_{\mathrm{ch}}-Z_{\mathrm{gr}}}{Z_{\mathrm{ch}}+Z_{\mathrm{gr}}}
\end{gathered}
$$

where $Z_{\mathrm{ob}}$ is the characteristic impedance of the strike object, $Z_{\mathrm{ch}}$ is the equivalent impedance of the lightning channel, and $Z_{\mathrm{gr}}$ is the grounding impedance. Table I summarizes relations between current reflection coefficients $\left(\rho_{\mathrm{bot}}, \rho_{\mathrm{top}}\right.$, and $\left.\rho_{\mathrm{gr}}\right)$ and pertinent impedances $\left(Z_{\mathrm{ob}}, Z_{\mathrm{ch}}\right.$, and $\left.Z_{\mathrm{gr}}\right)$ for four sets of $\rho_{\mathrm{top}}$, and $\rho_{\text {bot }}$ considered in this paper. It is clear from Table I that $\rho_{\text {gr }}$ is not an independent parameter; it is equal to $\rho_{\text {bot }}$ (as long as $Z_{\mathrm{ch}} \geq Z_{\mathrm{ob}} \gg Z_{\mathrm{gr}}$, which is expected in most practical situations).

This paper is organized as follows: In Section II, we present the methodology for examining electromagnetic coupling 


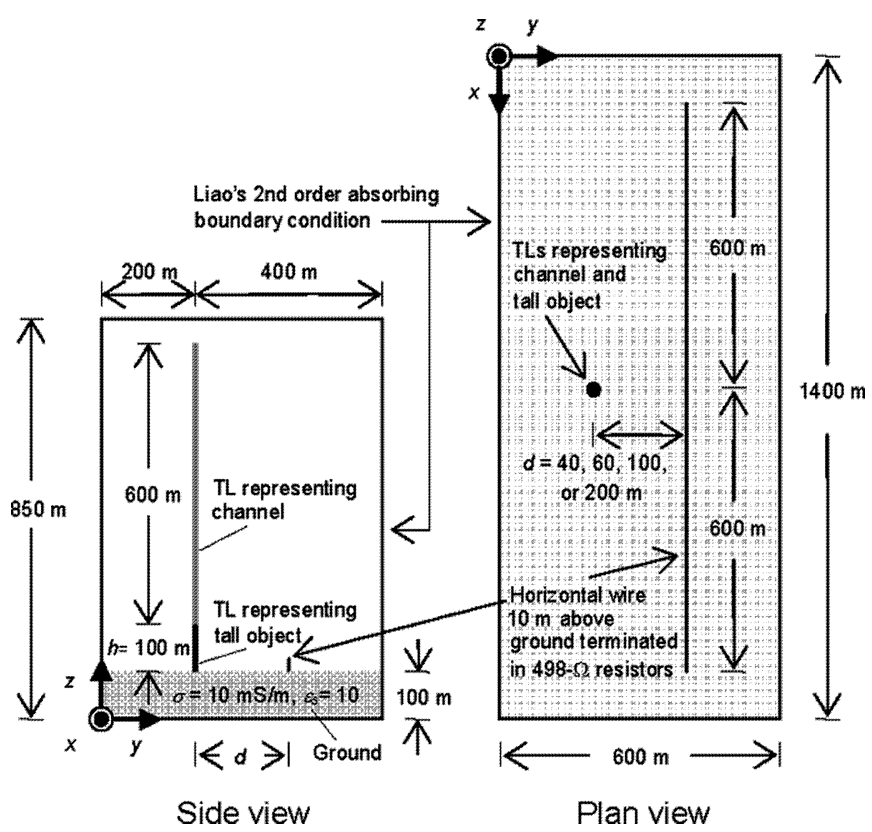

Fig. 1. A 1200-m-long horizontal perfectly conducting wire at distances $d=$ $40,60,100$, and $200 \mathrm{~m}$ from a tall object of height $h=100 \mathrm{~m}$ struck by lightning, to be analyzed using the FDTD method. The horizontal wire has a radius of $5 \mathrm{~mm}$ and is located $10 \mathrm{~m}$ above ground. Each end of the wire is terminated in a $498-\Omega$ matching resistor. The tall object and the lightning channel are represented by a vertical array of current sources specified using the "engineering" TL model extended to include a tall strike object [5]. The working volume of $1400 \times 600 \times 850 \mathrm{~m}^{3}$, which is divided into $5 \times 5 \times 5 \mathrm{~m}^{3}$ cubic cells, is surrounded by six planes of Liao's second-order absorbing boundary condition [28] in order to avoid reflections there.

between the lightning channel attached to a tall grounded object and a horizontal wire above ground. In Section III, we compare induced voltages due to a lightning strike to a 100 -m-high object with their counterparts due to the same strike to flat ground, calculated for different values of $d, \rho_{\mathrm{top}}, \rho_{\mathrm{bot}}$, and $\rho_{\mathrm{gr}}$. Further, we investigate the influences on the ratio of magnitudes of lightning-induced voltages for the tall-object and flat-ground cases of the return stroke speed $v$, the height of strike object $h$, and the RT of lightning return stroke current waveform. In Section IV, we compare the lightning-induced voltages calculated using the finite-difference time-domain (FDTD) method [26] with those calculated by Piantini and Janiszewski [11], [12] and by Silveira and Visacro [18]. In Appendix A, we show that for the case of strikes to flat ground, the FDTD method yields reasonably accurate results by comparing lightning-induced voltages calculated using our FDTD method with these measured by Ishii et al. [27] in a small-scale experiment and in Appendix B with those calculated using Rusck's formula [13]. In Appendix C, we compare induced voltages due to lightning strikes to a 200-m-high object calculated using the FDTD method with those measured by Michishita et al. [23].

\section{Methodology}

The model used in this study is presented in Fig. 1, which shows a horizontal perfectly conducting wire of length $1200 \mathrm{~m}$ and radius $5 \mathrm{~mm}$, at distances $d=40,60,100$, and $200 \mathrm{~m}$ from a tall object of height $h=100 \mathrm{~m}$ struck by lightning. The hori- zontal wire is located $10 \mathrm{~m}$ above ground. Each end of the wire is terminated in a $498-\Omega$ matching resistor. The conductivity, relative permittivity, and relative permeability of the ground are set to $\sigma=10 \mathrm{mS} / \mathrm{m}, \varepsilon_{r}=10$, and $\mu_{r}=1$, respectively. A 600-m-long vertical lightning channel is connected to the top of the tall object. The influence of reflections from the upper end of the 600-m-long channel does not appear in calculated waveforms of lightning-induced voltages within the first $4 \mu$ s examined in this paper. Lightning-induced voltage on the horizontal wire is evaluated by integrating the vertical electric field from the ground surface to the height of the wire. The electric field is calculated using the FDTD method of solving the discretized Maxwell's equations. Calculations are also carried out for the cases of lightning strike to flat lossy ground $(\sigma=10 \mathrm{mS} / \mathrm{m})$ and to flat perfectly conducting ground $(\sigma=\infty)$. The working volume of $1400 \times 600 \times 850 \mathrm{~m}^{3}$ (see Fig. 1) is divided into $5 \times 5 \times 5 \mathrm{~m}^{3}$ cubic cells and is surrounded by six planes of Liao's second-order absorbing boundary condition [28] to avoid reflections there. The 5-mmradius horizontal wire is represented in the FDTD procedure by a zero-radius wire (simulated by forcing the tangential components of electric field along the axis of the wire to zero) embedded in cells for which the relative permittivity is set to an artificially lower value and the relative permeability to an artificially higher value [29]. For our calculations, we set $\varepsilon_{r}$ and $\mu_{r}$ to 0.213 and 1/0.213, respectively (see Appendix A).

In order to find the distribution of current along both the lightning channel and the strike object, we use the "engineering" TL model extended to include a tall strike object [5]. The reason why we use the engineering TL model instead of an electromagnetic return stroke model [30], which would allow a self-consistent full-wave solution for both lightning-current distribution and fields needed to calculate voltages induced on the wire, is that the TL model allows one to set more directly the speeds of current waves along the tall object and the channel,as well as reflection coefficients at the extremities of the tall object. Evaluation of the dependence of lightning-induced voltages on the assumed values of these speeds and reflection coefficients is one of the main objectives of this study.

For the case of lightning strike to a tall object, equations for current, $I\left(z^{\prime}, t\right)$, along the tall object $\left(0 \leq z^{\prime} \leq h\right)$ and along the lightning channel $\left(z^{\prime} \geq h\right)$, are given by Baba and Rakov [5] and reproduced here:

$$
\begin{aligned}
& I\left(z^{\prime}, t\right)=\frac{1-\rho_{\mathrm{top}}}{2} \\
& \times \sum_{n=0}^{\infty}\left[\begin{array}{c}
\rho_{\mathrm{bot}}^{n} \rho_{\mathrm{top}}^{n} I_{\mathrm{sc}}\left(h, t-\frac{h-z^{\prime}}{c}-\frac{2 n h}{c}\right) \\
+\rho_{\mathrm{bot}}^{n+1} \rho_{\mathrm{top}}^{n} I_{\mathrm{sc}}\left(h, t-\frac{h+z^{\prime}}{c}-\frac{2 n h}{c}\right)
\end{array}\right] \\
& \quad \text { for } 0 \leq z^{\prime} \leq h \text { (along the strike object) } \\
& I\left(z^{\prime}, t\right)=\frac{1-\rho_{\mathrm{top}}}{2} \\
& \times\left[\begin{array}{c}
I_{\mathrm{sc}}\left(h, t-\frac{z^{\prime}-h}{v}\right) \\
+\sum_{n=1} \infty \rho_{\mathrm{bot}}^{n} \rho_{\mathrm{top}}^{n-1}\left(1+\rho_{\mathrm{top}}\right) I_{\mathrm{sc}}\left(h, t-\frac{z^{\prime}-h}{v}-\frac{2 n h}{c}\right)
\end{array}\right]
\end{aligned}
$$

for $z^{\prime} \geq h$ (along the lightning channel) 
where $I_{\mathrm{sc}}(h, t)$ is the lightning short-circuit current (which is defined as the lightning current that would be measured at an ideally grounded strike object of negligible height), $\rho_{\text {bot }}$ is the current reflection coefficient at the bottom of the tall object, $\rho_{\text {top }}$ is the current reflection coefficient at the top of the object for upward-propagating waves, $n$ is an index representing the successive multiple reflections occurring at the two ends of the tall object, $c$ is the speed of light (current propagation speed along the strike object), and $v$ is the current propagation speed along the channel.

Equations (2a) and (2b) are the same as equations (10a) and

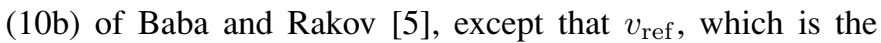
speed of current waves reflected from ground and then transmitted into the lightning channel, in (10b) is replaced by $v$ in (2b). Rationale for replacing $v_{\text {ref }}$ with $v$ is discussed by Baba and Rakov [5]. Equations (2a) and (2b) show that two current waves of the same magnitude $\left(1-\rho_{\text {top }}\right) I_{\mathrm{sc}}(h, t) / 2$ are initially injected downward, into the tall object, and upward, into the lightning channel.

The current distribution $I\left(z^{\prime}, t\right)$ along the lightning channel for the case of strike to flat ground is given by [5]

$$
I\left(z^{\prime}, t\right)=\frac{1+\rho_{\mathrm{gr}}}{2} I_{\mathrm{sc}}\left(0, t-\frac{z^{\prime}}{v}\right)
$$

where $I_{\mathrm{sc}}(0, t)$ is the lightning short-circuit current [same as $I_{\mathrm{sc}}(h, t)$ in (2a) and (2b) but injected at $z^{\prime}=0$ instead of at $\left.z^{\prime}=h\right]$ and $\rho_{\mathrm{gr}}$ is the current reflection coefficient at the channel base (ground). Note that when $h$ approaches zero, (2b) reduces to (3), and (2a) reduces to (3) with $z^{\prime}=0$ [5]. When $h \rightarrow 0$, terms in (2b) become $I_{\mathrm{sc}}\left(h, t-\left(z^{\prime}-h\right) / v\right) \simeq I_{\mathrm{sc}}(0, t-$ $\left.z^{\prime} / v\right), I_{\mathrm{sc}}\left(h, t-\left(z^{\prime}-h\right) / v-2 n h / c\right) \simeq I_{\mathrm{sc}}\left(0, t-z^{\prime} / v\right)$, and $\sum_{n=1}^{\infty} \rho_{\text {bot }}^{n-1} \rho_{\text {top }}^{n-1} \simeq 1 /\left(1-\rho_{\text {bot }} \rho_{\text {top }}\right)$, and when $h \rightarrow 0$ and $z^{\prime}=0$, terms in (2a) become $I_{\mathrm{sc}}\left(h, t-\left(h-z^{\prime}\right) / c-2 n h / c\right) \simeq$ $I_{\mathrm{sc}}(0, t), I_{\mathrm{sc}}\left(h, t-\left(h+z^{\prime}\right) / c-2 n h / c\right) \simeq I_{\mathrm{sc}}(0, t), \quad$ and $\sum_{n=0}^{\infty} \rho_{\text {bot }}^{n} \rho_{\text {top }}^{n} \simeq 1 /\left(1-\rho_{\text {bot }} \rho_{\text {top }}\right)$. The total charge transfer to ground, calculated integrating current given by (2a) at $z^{\prime}=0$, is the same as that calculated integrating current given by (3) at $z^{\prime}=0$ [4]. Therefore, current distributions for the case of strikes to a tall object $[(2 a)$ and $(2 b)]$ and for the case of strikes to flat ground (3) correspond to the same lightning discharge, as required for examining the influence of the strike object. On the other hand, currents injected into the lightning channel in the following two cases are generally different: $I=\left(1-\rho_{\text {top }}\right) I_{\mathrm{sc}} / 2$ vs. $I=\left(1+\rho_{\mathrm{gr}}\right) I_{\mathrm{sc}} / 2$, unless $\rho_{\text {top }}=0$ and $\rho_{\mathrm{gr}}=0$ (matched conditions at the position of the source) or $\rho_{\mathrm{top}}=-\rho_{\mathrm{gr}}\left(Z_{\mathrm{ob}}=\right.$ $\left.Z_{\text {gr }}\right)$. Both these situations are physically unrealistic because typically, $\rho_{\mathrm{gr}}=1\left(Z_{\mathrm{gr}} \ll Z_{\mathrm{ob}}\right.$ and $\left.Z_{\mathrm{gr}} \ll Z_{\mathrm{ch}}\right)$.

In the FDTD calculations, the lightning channel and the tall strike object are each simulated by a vertical array of current sources [31]. Each current source has a length of $5 \mathrm{~m}$ and is described by specifying the four magnetic-field vectors forming a square contour surrounding the cubic cell representing the current source [31].

Lightning-induced voltages are calculated at the center point of the horizontal wire with a time increment of $5 \mathrm{~ns}$. Verification of the applicability of the FDTD approach to the calculation of lightning-induced voltages is presented in Appendixes A-C.

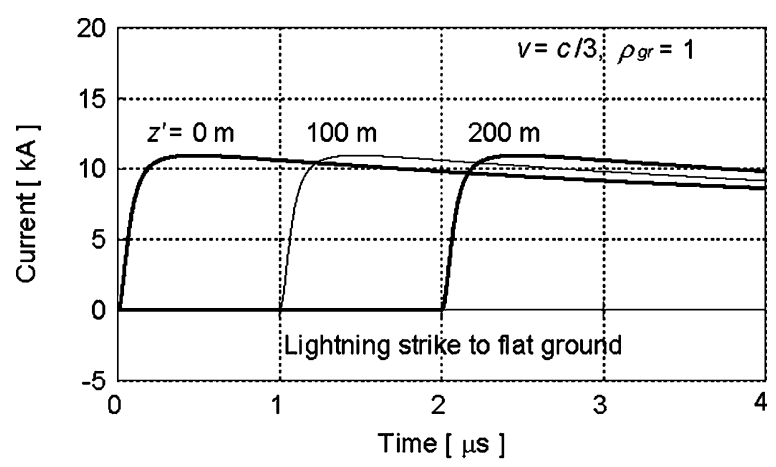

(a)

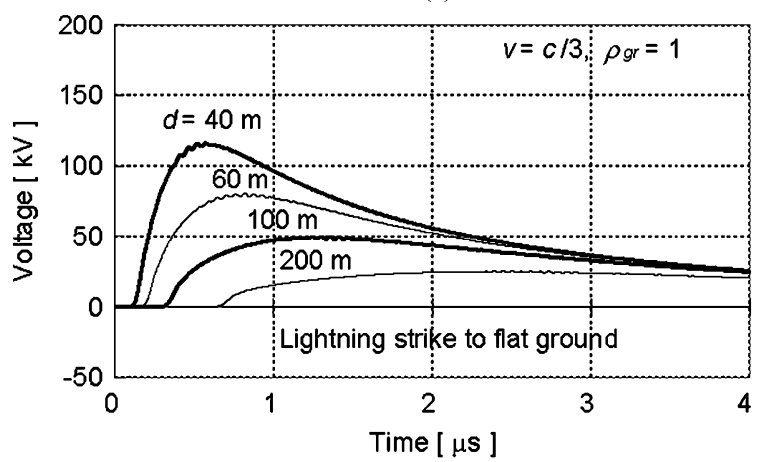

(b)

Fig. 2. (a) Current waveforms for a strike to flat ground $(v=c / 3$, and $\left.\rho_{\text {gr }}=1\right)$ at different heights $z^{\prime}=0,100$, and $200 \mathrm{~m}$ along the lightning channel, calculated using (3). (b) Lightning-induced voltages at the center point of the horizontal wire at distances $d=40,60,100$, and $200 \mathrm{~m}$ from the lightning channel, calculated using the FDTD method.

\section{ANALYSIS AND RESULTS}

In this section, we compare induced voltages on the wire (see Fig. 1) due to a lightning strike to the 100-m-high object with their counterparts due to the same strike to flat ground. We start with perhaps the most realistic situation in which $v=c / 3$ [32], the current reflection coefficient at the bottom of the object is $\rho_{\mathrm{bot}}=1\left(Z_{\mathrm{ob}}\right.$ is usually much larger than $\left.Z_{\mathrm{gr}}\right)$, and the current reflection coefficient at the top of the tall object is $\rho_{\text {top }}=-0.5$. Note that Janischewskyj et al. [33], from their analysis of five current waveforms measured $474 \mathrm{~m}$ above ground on the $\mathrm{CN}$ Tower, inferred $\rho_{\text {top }}$ to vary from -0.27 to -0.49 , and Fuchs [34], from 13 simultaneous current measurements at the top and bottom of the Peissenberg tower, found $\rho_{\text {top }}$ to vary from -0.39 to -0.68 . In the case of lightning strike to flat ground, we assume that the current reflection coefficient at the channel base (ground) is $\rho_{\mathrm{gr}}=1$ ( $Z_{\mathrm{ch}}$ is much larger than $Z_{\mathrm{gr}}$ at the strike point). The assumption of $\rho_{\mathrm{gr}}=1$ is supported by the inference that lightning is capable of lowering its grounding impedance to a value that is always much lower than the equivalent impedance of the lightning channel [8], [35]. We describe $I_{\mathrm{sc}}(h, t)$ or $I_{\mathrm{sc}}(0, t)$ using a current waveform proposed by Nucci et al. [36], which is thought to be typical for lightning subsequent return strokes. The zero-to-peak RT of this current waveform is about $0.5 \mu \mathrm{s}$ (the corresponding 10-90\% RT is $0.15 \mu \mathrm{s}$ ).

Fig. 2(a) shows current waveforms at different heights $z^{\prime}=0$, 100 , and $200 \mathrm{~m}$, along the lightning channel for a lightning strike to flat ground, calculated using (3). Fig. 2(b) shows 


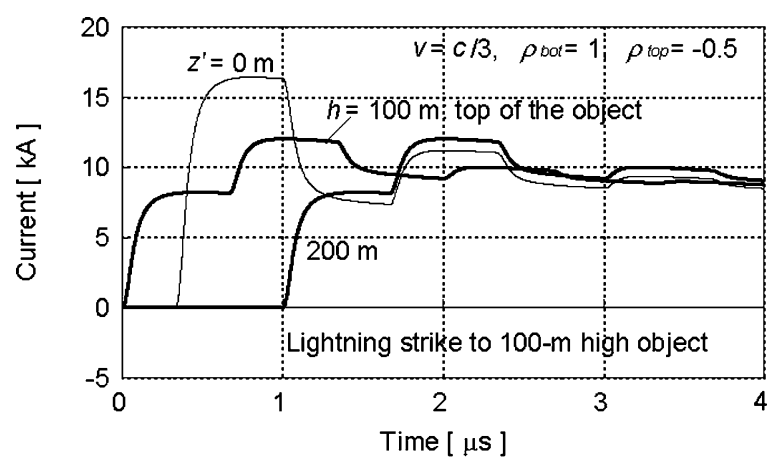

(a)

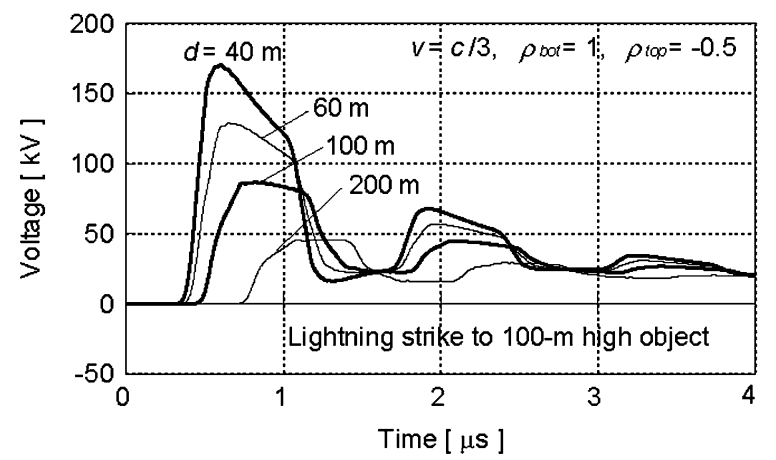

(b)

Fig. 3. (a) Current waveforms for a strike to the 100-m-high object at different heights above ground $z^{\prime}=0$ (bottom of the tall object), $100 \mathrm{~m}$ (top of the object and bottom of the channel), and $200 \mathrm{~m}$ (100 m above the top of the object), calculated using (2a) and (2b). (b) Lightning-induced voltages at the center point of the horizontal wire at distances $d=40,60,100$, and $200 \mathrm{~m}$ from the strike object, calculated using the FDTD method. Note that voltage magnitudes in (b) are higher than their counterparts for the flat-ground case shown in Fig. 2(b) for all the distances considered.

corresponding lightning-induced voltages at the center point of the horizontal wire at distances $d=40,60,100$, and $200 \mathrm{~m}$ from the lightning channel. As expected, the voltage magnitude decreases with increasing distance. Fig. 3(a) and (b) is similar to Fig. 2(a) and (b) but for the case of lightning strike to the 100-m-high object. Fig. 3(a) shows current waveforms at different heights, $z^{\prime}=0$ (bottom of the tall object), 100 (top of the object and bottom of the channel), and $200 \mathrm{~m}(100 \mathrm{~m}$ above the top of the object), calculated using (2a) and ( $2 b)$, and Fig. 3(b) shows corresponding lightning-induced voltages. The magnitude of lightning-induced voltage is always larger in the case of lightning strike to the 100-m-high object than in the case of the same strike to flat ground, regardless of the distance between the channel/strike object and the horizontal wire. The ratios of magnitudes of lightning-induced voltages for the tallobject case to that for the flat-ground case are 1.5, 1.6, 1.7, and 1.8 for $d=40,60,100$, and $200 \mathrm{~m}$, respectively. Note that these ratio values for $\sigma=10 \mathrm{mS} / \mathrm{m}$ are not much different from their counterparts computed assuming perfectly conducting ground $(\sigma=\infty): 1.5,1.7,2.0$, and 2.2 for $d=40,60,100$, and $200 \mathrm{~m}$, respectively. Also note that the difference between magnitudes of lightning-induced voltages at the center point of the horizontal wire located $10 \mathrm{~m}$ above perfectly conducting ground for a lightning strike to flat ground calculated using the FDTD method and those calculated using Rusck's formula [13]

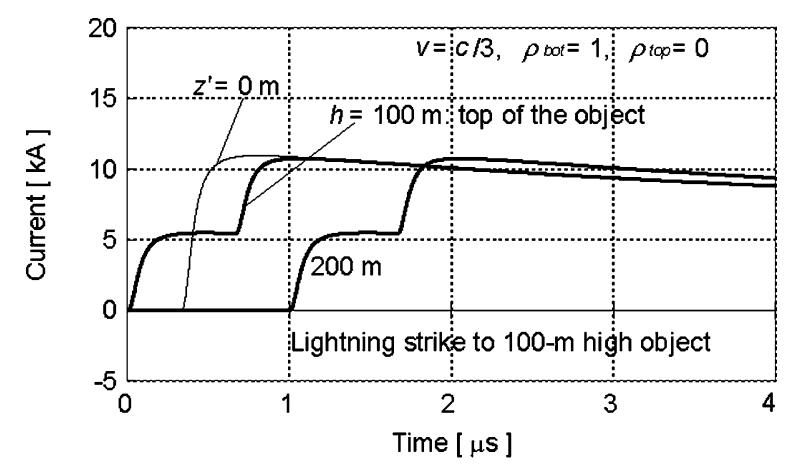

(a)

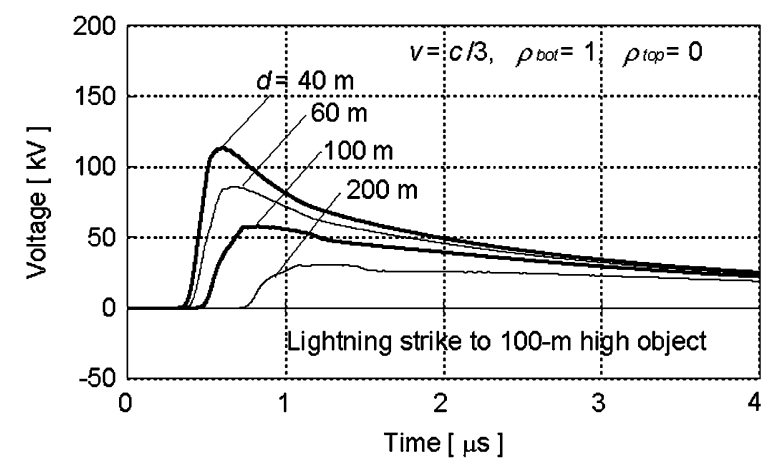

(b)

Fig. 4. Same as Fig. 3 but for $\rho_{\text {top }}=0$. Note that voltage magnitudes in (b) are lower at $d=40 \mathrm{~m}$ and higher at $d=60,100$, and $200 \mathrm{~m}$ than their counterparts for the flat-ground case in Fig. 2(b).

is within 5\% at $d$ ranging from 40 to $200 \mathrm{~m}$ (see Appendix B). In summary, it is clear that for RT $=0.5 \mu \mathrm{s}, v=c / 3, \rho_{\text {top }}=-0.5$, and $\rho_{\text {bot }}=1$, lightning-induced voltages at distances ranging from 40 to $200 \mathrm{~m}$ are enhanced by the presence of the $100-\mathrm{m}$ high strike object.

We next consider the case of $v=c / 3, \rho_{\text {top }}=0$, and $\rho_{\text {bot }}=1$, which differs from the previously discussed (basic) case by the value of $\rho_{\mathrm{top}}$. The assumption $\rho_{\mathrm{top}}=0$ implies that $Z_{\mathrm{ob}}=$ $Z_{\mathrm{ch}}$ (matched conditions at the top of the object). Fig. 4(a) shows current waveforms at different heights, $z^{\prime}=0,100$, and $200 \mathrm{~m}$, for a lightning strike to the 100-m-high object, and Fig. 4(b) shows corresponding lightning-induced voltages. The magnitude of lightning-induced voltage at $d=40 \mathrm{~m}$ is a little smaller in the case of lightning strike to the tall object than in the case of the same lightning strike to flat ground [see Fig. 2(b)] and larger at $d=60,100$, and $200 \mathrm{~m}$. Thus, for $v=c / 3, \rho_{\text {top }}=0$, and $\rho_{\text {bot }}=1$, lightning-induced voltages are reduced at $d=$ $40 \mathrm{~m}$ (and at smaller distances) and enhanced for $d$ ranging from 60 to $200 \mathrm{~m}$ by the presence of the $100-\mathrm{m}$ high strike object.

We now consider the unrealistic but sometimes assumed case of $\rho_{\text {bot }}=0$ and summarize all results of this section in Fig. 5, which shows ratios of magnitudes of lightning-induced voltages for the tall-object and flat-ground cases for $v=c / 3$ and different values of $\rho_{\text {top }}, \rho_{\text {bot }}$, and $\rho_{\mathrm{gr}}=\rho_{\text {bot }}$ (except for $\left.\rho_{\text {bot }}=0\right)$. In the case of $\rho_{\text {bot }}=0\left(Z_{\mathrm{gr}}=Z_{\mathrm{ob}}\right), \rho_{\mathrm{gr}}$ becomes equal to $-\rho_{\text {top }}$. Thus, the magnitudes of current waves injected into both the lightning channel and the strike object for strikes to tall object, $\left(1-\rho_{\text {top }}\right) I_{\mathrm{sc}} / 2$, become equal to that injected 


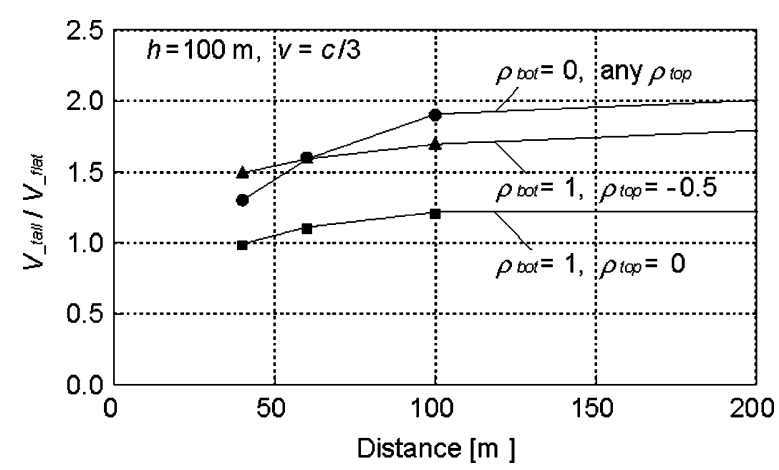

Fig. 5. Ratios of magnitudes of lightning-induced voltages for tall-object $(h=$ $100 \mathrm{~m})$ and flat-ground cases for different values of $\rho_{\text {top }}$ and $\rho_{\text {bot. }}$. Note that $\rho_{\mathrm{gr}}=\rho_{\text {bot }}$, except for $\rho_{\text {bot }}=0$. In the latter case $\left(Z_{\mathrm{gr}}=Z_{\mathrm{ob}}\right), \rho_{\mathrm{gr}}=-\rho_{\mathrm{top}}$ (see Table I), and $V_{\text {ttall }} / V_{\text {-flat }}$ is the same for any value of $\rho_{\text {top }}$. Current waves are assumed to propagate at speed $c$ along the strike object and at speed $v=c / 3$ along the lightning channel.

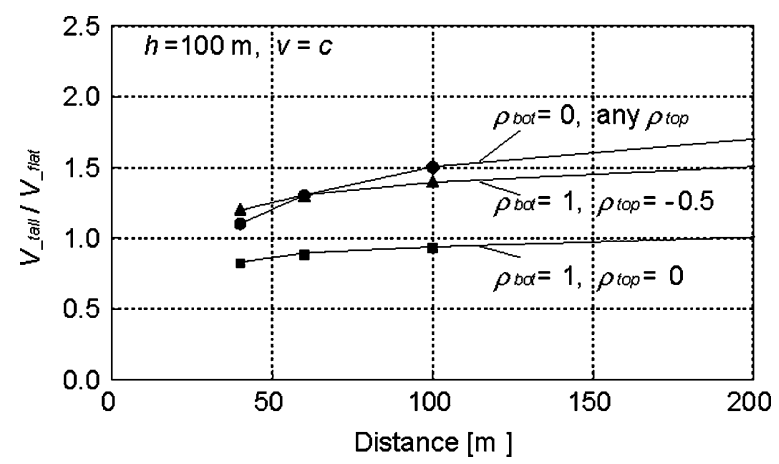

Fig. 6. Same as Fig. 5 but for the case of $v=c$.

into the channel for strikes to flat ground, $\left(1+\rho_{\mathrm{gr}}\right) I_{\mathrm{sc}} / 2$. As a result, the ratio of magnitudes of lightning-induced voltages for tall-object and flat-ground cases becomes independent of $\rho_{\text {top }}$. It is clear from Fig. 5 that the ratio increases with decreasing $\rho_{\text {bot }}\left(\rho_{\text {bot }}<1\right)$, decreasing $\rho_{\text {top }}\left(\rho_{\text {top }}<0\right.$, except for the case of $\rho_{\text {bot }}=0$ ), and with increasing distance $d$. This tendency is similar to that observed by Baba and Rakov [4] for the vertical electric field or azimuthal magnetic field at ground level at distances $d=40-200 \mathrm{~m}$. The ratio decreases with increasing $v$, as follows from a comparison of Fig. $5(v=c / 3)$ with Fig. 6, in which $v=c$ (the limiting value). As seen in Fig. 6, the lightning-induced voltage is reduced at $d$ ranging from 40 to $200 \mathrm{~m}$ due to the presence of the 100-m-high strike object when $v=c, \rho_{\text {top }}=0$, and $\rho_{\text {bot }}=\rho_{\mathrm{gr}}=1$.

We additionally examine the magnitude of lightninginduced voltage as a function of the strike-object (junction point) height $h$ at $d=100 \mathrm{~m}$. Fig. 7(a) shows lightninginduced voltages calculated using the FDTD method for $v=c / 3, \rho_{\text {top }}=0, \rho_{\text {bot }}=\rho_{\text {gr }}=0$, and $h=0,25,50,100$, 200 , and $300 \mathrm{~m}$. Fig. 7(b) shows ratios of magnitudes of lightning-induced voltages at $d=100 \mathrm{~m}$ for tall-object and flatground cases computed using different sets of $\rho_{\text {top }}$ and $\rho_{\text {bot }}$. It is clear from Fig. 7 that the ratio increases with increasing $h$ up to $100 \mathrm{~m}$ and then decreases with increasing $h$. Fig. 8 , which is the same as Fig. 7(b) but for $v=c$, suggests that, except for the case of $\rho_{\mathrm{top}}=0$ and $\rho_{\mathrm{bot}}=1$, the ratio at $d=100 \mathrm{~m}$ increases

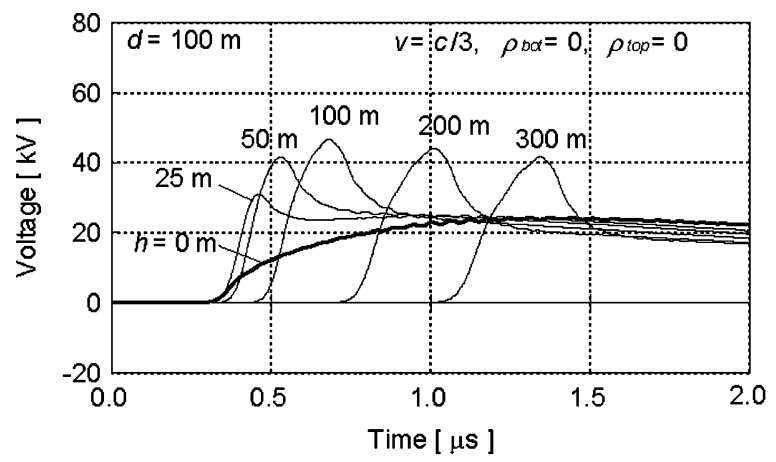

(a)

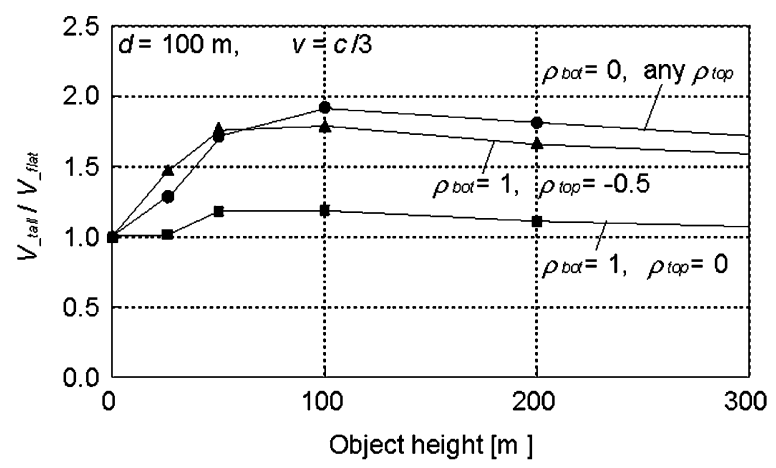

(b)

Fig. 7. (a) Lightning-induced voltages at the center point of the horizontal wire at a distance of $d=100 \mathrm{~m}$ from the strike object, calculated using the FDTD method for $\rho_{\mathrm{top}}=0, \rho_{\mathrm{bot}}=0$, and different strike object heights, $h=0,25$, $50,100,200$, and $300 \mathrm{~m}$. (b) Ratios of magnitudes of lightning-induced voltages at $d=100 \mathrm{~m}$ for $h$ ranging from 0 to $300 \mathrm{~m}$ to that for $h=0$ (strike to flat ground) for different values of $\rho_{\mathrm{top}}, \rho_{\mathrm{bot}}$, and $\rho_{\mathrm{gr}}$. Current waves are assumed to propagate at speed $c$ along the strike object and at speed $v=c / 3$ along the lightning channel.

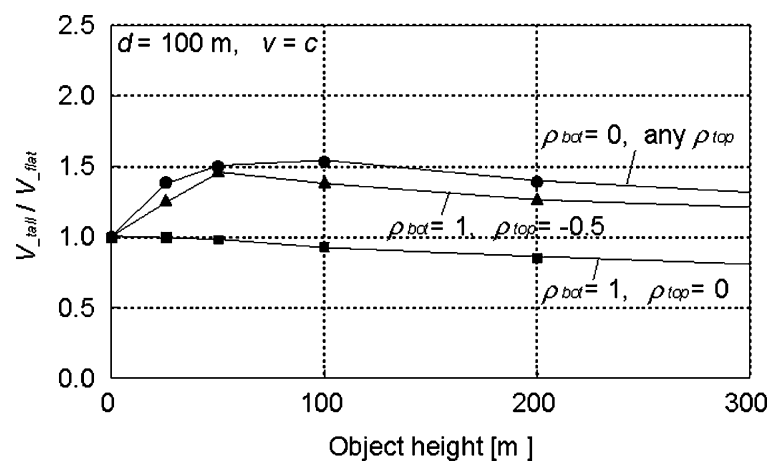

Fig. 8. Same as Fig. 7(b) but for $v=c$.

with increasing $h$ up to $50-100 \mathrm{~m}$ and then decreases with increasing $h$. When $\rho_{\text {top }}=0$ and $\rho_{\text {bot }}=1$, the ratio decreases monotonically with increasing $h$. It follows from comparison of Figs. 7 and 8 that the ratio decreases with increasing $v$.

Finally, we consider the lightning-induced voltage as a function of RT of the lightning (short-circuit) current $I_{\mathrm{sc}}$. The waveform of $I_{\mathrm{sc}}$ is approximated by an expression containing the so-called Heidler function, and the zero-to-peak RTs are set to about $0.5 \mu \mathrm{s}$, as in the basic case, $1 \mu \mathrm{s}$, and $3 \mu \mathrm{s}$ (the corresponding $10-90 \%$ RTs are $0.15,0.39$, and $1.42 \mu \mathrm{s}$, respectively). Fig. 9(a) shows ratios of magnitudes of lightning-induced 


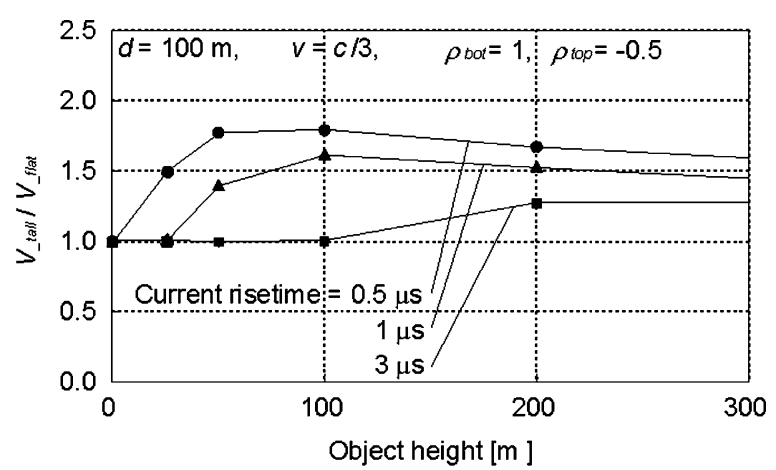

(a)

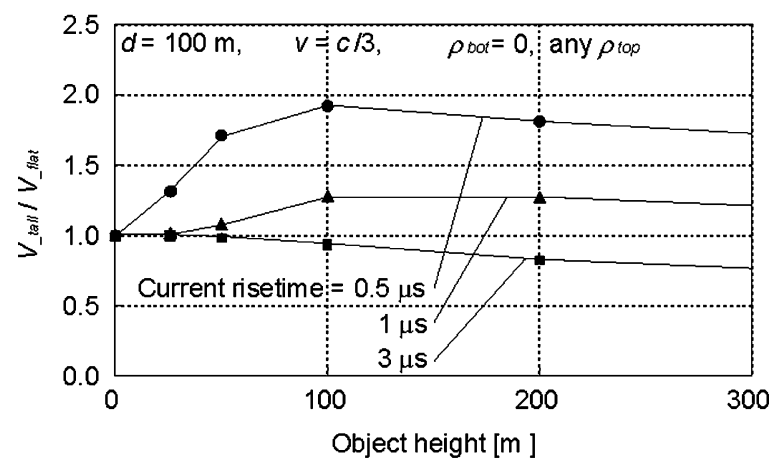

(b)

Fig. 9. Ratios of magnitudes of lightning-induced voltages at $d=100 \mathrm{~m}$ for $h$ ranging from 0 to $300 \mathrm{~m}$ to that for $h=0$ (strike to flat ground) for different zero-to-peak RTs of the lightning (short-circuit) current $I_{\mathrm{sc}}, 0.5 \mu \mathrm{s}, 1 \mu \mathrm{s}$, and $3 \mu$ s for (a) $\rho_{\text {top }}=-0.5$ and $\rho_{\text {bot }}=1$ and (b) $\rho_{\text {bot }}=0$ and any $\rho_{\text {top }}$. Current waves are assumed to propagate at speed $c$ along the strike object and at speed $v=c / 3$ along the lightning channel.

voltages at $d=100 \mathrm{~m}$ for the tall-object and flat-ground cases for $\rho_{\text {top }}=-0.5$ and $\rho_{\text {bot }}=1$ and different current RTs. Fig. 9(b) is the same as Fig. 9(a) but for $\rho_{\text {bot }}=0$. When $\rho_{\text {bot }}=0$ and the RT of $I_{\mathrm{sc}}$ is $3 \mu \mathrm{s}$, the ratio is less than unity and decreases monotonically with increasing $h$. It follows from Fig. 9 that the ratio increases with decreasing the RT of lightning current waveform. Note that ratios of magnitudes of vertical electric fields at $d=100 \mathrm{~m}$ for the tall-object and flat-ground cases for $\rho_{\text {bot }}=0$ significantly decrease with increasing $h$ regardless of the RT of $I_{\mathrm{sc}}$, while those of azimuthal magnetic fields at the same point increase more significantly as the RT of $I_{\mathrm{sc}}$ decreases (corresponding figures are not shown in this paper). Thus, when a slow-front lightning current is injected, the increase in the azimuthal magnetic field cannot compensate the significant decrease in the vertical electric field. This results in a decrease in the lightning-induced voltage (relative to the flat-ground case) for slow-front lightning currents $(\mathrm{RT}=3 \mu \mathrm{s})$ that is seen in Fig. 9(b).

\section{DISCUSSION}

\section{A. Comparison With Calculations of Piantini and Janiszewski} [11], [12]

Piantini and Janiszewski [11], considering a return stroke initiated at the attachment point of the descending leader to the top of a tall strike object, have shown that the magnitude of

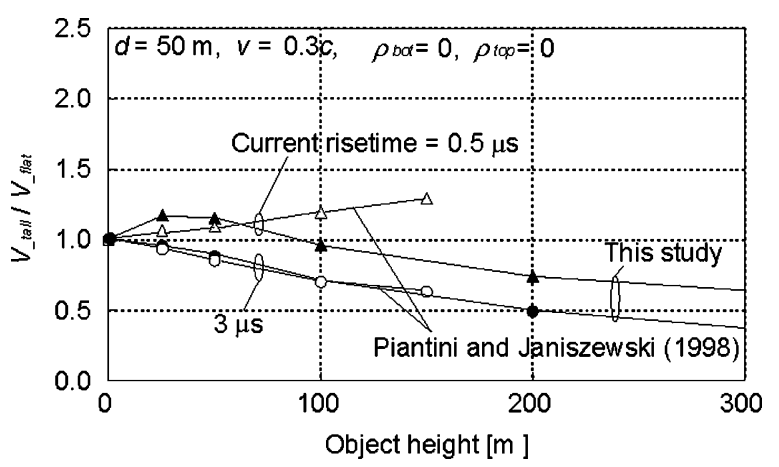

Fig. 10. Ratios of magnitudes of lightning-induced voltages at $d=50 \mathrm{~m}$ for $h$ ranging from 0 to $300 \mathrm{~m}$ to that for $h=0$ (strike to flat ground) calculated using the FDTD method (solid triangles and solid circles) for $\rho_{\text {bot }}=0$ and $\rho_{\text {top }}=0$. The lightning current is assumed to rise linearly to its maximum in $0.5 \mu \mathrm{s}$ (triangles) or $3 \mu \mathrm{s}$ (circles) and to propagate at speed $c$ along the strike object and at speed $v=0.3 \mathrm{c}$ along the lightning channel. Ratios calculated for the same conditions by Piantini and Janiszewski [11] are shown by hollow triangles and hollow circles.

lightning-induced voltage on a 5-km-long horizontal wire, located $10 \mathrm{~m}$ above perfectly conducting ground and $50 \mathrm{~m}$ away from the strike object, increases with increasing the height of the strike object for a lightning current waveform having a RT of 0.5 $\mu \mathrm{s}$ (rising linearly to its maximum) and decreases for a current waveform having an RT $1 \mu$ s or longer (also rising linearly to its maximum). They used the TL model [37] and assumed that the return stroke speed $v=0.3 \mathrm{c}$. Further, they assumed that no reflections occur at the top or at the bottom of the object. We can represent this situation by setting $\rho_{\text {top }}=\rho_{\text {bot }}=\rho_{\text {gr }}=0$ and $v=0.3 \mathrm{c}$ in (1a), (1b), and (2). Fig. 10 shows ratios of magnitudes of lightning-induced voltages on a 1200 -m-long horizontal wire, matched at both ends, located $10 \mathrm{~m}$ above perfectly conducting ground at $d=50 \mathrm{~m}$ for the tall-object and flat-ground cases, calculated for the above conditions. Note that in these calculations, the lightning current was assumed to rise linearly to its maximum in 0.5 or $3 \mu \mathrm{s}$. The ratios calculated by Piantini and Janiszewski [11] at a distance of $d=50 \mathrm{~m}$ are also shown (see hollow triangles and circles). The trends predicted by both models agree well, except for the cases when $h \geq 50 \mathrm{~m}$ and the lightning-current RT is $0.5 \mu \mathrm{s}$. When the RT of the lightning current is $3 \mu \mathrm{s}$ or longer and $\rho_{\mathrm{bot}}=0$, the ratios are less than unity, which indicates a decrease in the induced voltage with increasing strike-object height. Piantini and Janiszewski [11] attributed the difference in trends for $\mathrm{RT}=0.5 \mu \mathrm{s}$ (hollow triangles in Fig. 10) and RT $=3 \mu$ s (hollow circles in Fig. 10) to different relative contributions of the static and induction components of lightning electric field. Interestingly, results of Piantini and Janiszewski for RT $=0.5 \mu$ s appear to be qualitatively consistent with those of Silveira and Visacro (discussed in Section IV-B; see Fig. 12), although the latter are for RT $=1 \mu \mathrm{s}$, for which Piantini and Janiszewski found the opposite trend.

Piantini and Janiszewski [12] have also shown that the magnitude of the lightning-induced voltage on a 5-km-long horizontal wire located $10 \mathrm{~m}$ above perfectly conducting ground and $60 \mathrm{~m}$ away from the lightning channel decreases as the height of the junction point between the descending and upward connecting leaders gets larger for a lightning current waveform having an 


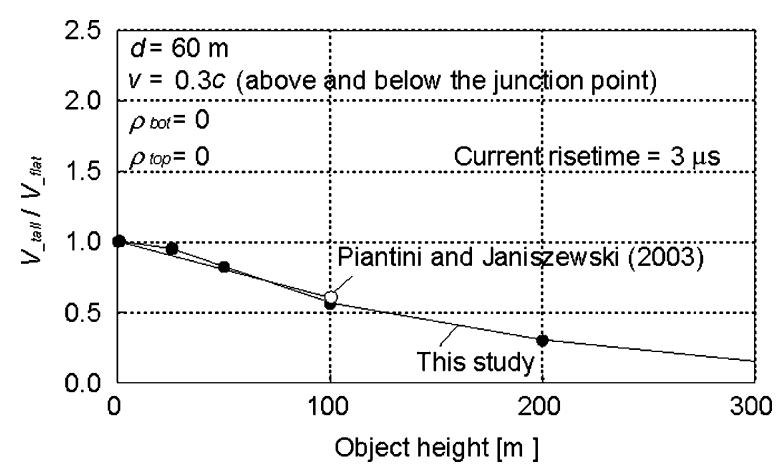

Fig. 11. Ratios of magnitudes of lightning-induced voltages at $d=60 \mathrm{~m}$ for heights $h$ of the junction point between the descending and upward connecting leaders ranging from 0 to $300 \mathrm{~m}$ to that for $h=0$ (strike to flat ground without an upward connecting leader), calculated using the FDTD method (solid circles) for $\rho_{\text {bot }}=0$ and $\rho_{\text {top }}=0$. Lightning current is assumed to rise linearly to its maximum in $3 \mu$ s and to propagate at speed $0.3 c$ along the leader channels both above and below the junction point. Ratios calculated for the same conditions by Piantini and Janiszewski [12] are shown by hollow circles.

RT of $3 \mu \mathrm{s}$ (rising linearly to its maximum). Note that conceptually, an upward connecting leader in this study can be viewed as a tall grounded strike object, which allows us to apply here the methodology described in Section II. In doing so, we relax the assumption that waves always propagate at speed $c$ along the strike object. Piantini and Janiszewski [12] assumed that both upward and downward current waves propagated from the junction point at the same speed $0.3 \mathrm{c}$. They seem to have assumed that no reflections occur at the top and bottom of the upward connecting leader. We can represent this situation by using $\mathrm{RT}=3 \mu \mathrm{s}$, setting $\rho_{\mathrm{top}}=\rho_{\mathrm{bot}}=\rho_{\mathrm{gr}}=0$, and replacing all the speeds (including $c$ ) in (1a), (1b), and (2) with $0.3 c$. Fig. 11 shows the ratios of magnitudes of lightning-induced voltages on a 1200-m-long horizontal wire, matched at both ends, located $10 \mathrm{~m}$ above perfectly conducting ground at $d=60 \mathrm{~m}$ for the tall-object and flat-ground cases, calculated for the above conditions. The ratios calculated by Piantini and Janiszewski [12] are also shown (see hollow circles). The trends predicted by both models agree well. The ratios are less than unity, which indicates a decrease in induced voltage with an increase in the junction point height.

Note that a decrease in the induced voltage at a distance of about $50 \mathrm{~m}$ due to the presence of 30-m-long upward connecting leader was predicted by Wagner and McCann [38, Fig. 16].

\section{B. Comparison With Calculations of Silveira and Visacro [20]}

As noted in Section I, Silveira and Visacro [20] and Silveira et al. [21], considering a return stroke initiated at the junction point between the descending and upward connecting leaders, have found that the magnitude of the lightning-induced voltage on a 300-m-long horizontal wire (matched at both ends) located $10 \mathrm{~m}$ above perfectly conducting ground and $100 \mathrm{~m}$ away from the vertical lightning channel increased with an increase in the height of the junction point between the descending and upward connecting leaders. For example, according to Silveira and Visacro, the magnitude of the lightning-induced voltage increases by a factor of 1.3 or 2.0 as the height of the junc-

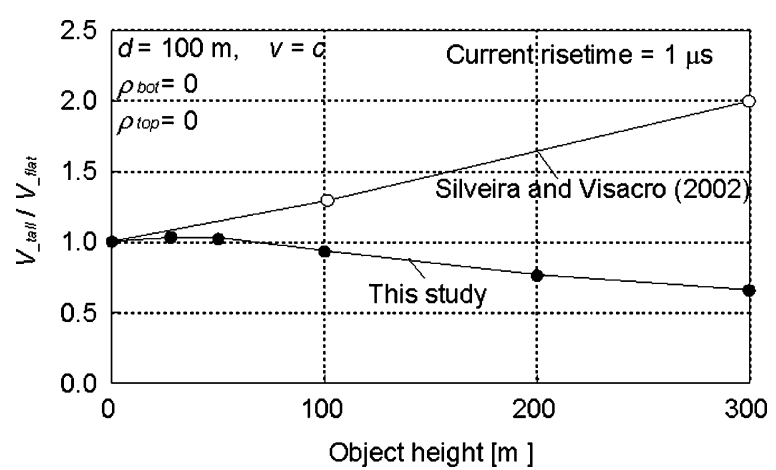

Fig. 12. Ratios of magnitudes of lightning-induced voltages at $d=100 \mathrm{~m}$ for junction point heights $h$ ranging from 0 to $300 \mathrm{~m}$ to that for $h=0$ (strike to flat ground without an upward connecting leader), calculated using the FDTD method (solid circles) for $\rho_{\text {bot }}=0$ and $\rho_{\text {top }}=0$. Current pulses having RT of $1 \mu \mathrm{s}$ are assumed to propagate at speed $c$ along the leader channels both above and below the junction point. Ratios calculated for the same conditions by Silveira and Visacro [20] are shown by hollow circles.

tion point increases from $h=0$ to 100 or $300 \mathrm{~m}$, respectively. Silveira and Visacro [20] used a model based on the hybrid electromagnetic field/circuit theory approach [22]. They used a current waveform linearly rising to its maximum value in 1 $\mu$ s and assumed that the current wave propagation speed along the leader channels both above and below the junction point was equal to $c$. Also, they apparently assumed that the current reflection coefficients at the top and bottom of the upward connecting leader were equal to zero. Thus, by setting $v=c$ and $\rho_{\text {top }}=\rho_{\text {bot }}=\rho_{\text {gr }}=0$ in (2a), (2b), and (3), we can simulate the current distribution used by Silveira and Visacro [20] and compute corresponding induced voltages on the overhead wire. Calculations were performed for $d=100 \mathrm{~m}$ and different values of $h$ ranging from 0 to $300 \mathrm{~m}$. Resultant ratios of magnitudes of lightning-induced voltages on the 300-m-long horizontal wire (matched at both ends) located $10 \mathrm{~m}$ above perfectly conducting ground for the tall-object and flat-ground cases are shown, along with Silveira and Visacro results, in Fig. 12, both calculated for a current waveform linearly rising to its maximum in $1 \mu \mathrm{s}$. Note that the FDTD-calculated results shown in Fig. 12 are obtained for the 300-m-long horizontal wire (the same length as that used by Silveira and Visacro [20]), but they are quite similar to those (not shown in this paper) obtained for the 1200-m-long horizontal wire (see Fig. 1). The increasing trend (voltage enhancement effect) for $h=100 \mathrm{~m}$ and $300 \mathrm{~m}$ reported by Silveira and Visacro [20] (see hollow circles in Fig. 12) is not consistent with the prediction of our model. According to Visacro (personal communication, Nov. 2005), this increasing trend resulted from a computation error.

\section{CONCLUSION}

We examined, using the FDTD method, the ratios of magnitudes of lightning-induced voltages for the cases of strikes to a 100 -m-high object and to flat ground as a function of distance from the lightning channel $d$, current reflection coefficients at the top of the strike object $\rho_{\text {top }}$, and at the bottom of the strike object $\rho_{\text {bot }}$, the current reflection coefficient at the channel base (in the 
case of strikes to flat ground) $\rho_{\mathrm{gr}}$, and the return stroke speed $v$. The validity of our FDTD calculations was demonstrated for strikes to flat ground and to a tall object by comparing FDTDcalculated voltage waveforms with the corresponding measured ones (see Appendix A). The ratio of magnitudes of lightninginduced voltages for tall-object and flat-ground cases increases with increasing $d$, decreasing $\rho_{\text {bot }}(<1)$, decreasing $\rho_{\text {top }}(<0$, except for the case of $\left.\rho_{\text {bot }}=0\right)$, and decreasing $v(<c)$. The ratio is larger than unity (strike object serves to enhance the induced voltage) for $d=40-200 \mathrm{~m}$ and realistic conditions such as $\rho_{\text {bot }}=\left(\rho_{\text {gr }}\right)=1, \rho_{\text {top }}=-0.5$, and $v=c / 3$, but becomes smaller than unity (lightning-induced voltage for the tall-object case is smaller than for the flat-ground case) under some special conditions such as $\rho_{\text {bot }}=\left(\rho_{\text {gr }}\right)=1, \rho_{\text {top }}=0$, and $v=c$.

Further, we investigated the influence of the strike-object height, $h$, at a distance of $d=100 \mathrm{~m}$. We found that, in perhaps the most realistic case $\left(\rho_{\mathrm{bot}}=\left(\rho_{\mathrm{gr}}\right)=1, \rho_{\mathrm{top}}=-0.5\right.$, and $v=c / 3$ ), the ratio of magnitudes of lightning-induced voltages increased with increasing $h$ from 0 to $100 \mathrm{~m}$ and decreased with increasing $h$ from 100 to $300 \mathrm{~m}$. In a less-realistic case, ( $\rho_{\text {bot }}=\left(\rho_{\text {gr }}\right)=1, \rho_{\text {top }}=0$, and $\left.v=c\right)$, the ratio was less than unity and decreased monotonically with increasing $h$. Also, the ratio was found to increase with decreasing the RT of lightning return stroke current waveform. Our results for relatively long current RTs $(3 \mu \mathrm{s})$ are in good agreement with those of Piantini and Janiszewski (1998), but for relatively short RTs (0.5 $\mu \mathrm{s})$, different trends are observed. Both our and Piantini and Janiszewski's results for the current RT equal to $1 \mu$ s disagree with those of Silveira and Visacro (2002).

The above findings regarding the lightning-induced voltages in the presence of a tall strike object have important implications for optimizing lightning protection means for telecommunication and power distribution lines.

\section{APPENDIX A}

\section{TESTING THE VALIDITY OF THE FDTD CALCULATIONS AGAINST EXPERIMENTAL DATA (STRIKES TO FLAT GROUND)}

The FDTD method is used to solve the discretized Maxwell's equations to find lightning electromagnetic fields and the reaction (scattered fields) of the overhead wire to these fields. The induced voltage on a horizontal wire is calculated by integrating the vertical electric field from the ground surface to the wire height. We show in this appendix that our FDTD method yields reasonably accurate lightning-induced voltages for the case of strikes to flat ground. In order to do this, we compare lightning-induced voltages calculated using the FDTD method with those measured by Ishii et al. [27] in a small-scale experiment. In their experiment, a lightning return stroke channel was represented by a coiled wire of length $28 \mathrm{~m}$. One end of this coiled wire was connected to a pulse generator, and the other end was kept open. The current waveform injected into the wire was measured using a current transformer. The apparent propagation speed of current wave along this wire was $125 \mathrm{~m} / \mu \mathrm{s}$. Another wire that was $0.25 \mathrm{~mm}$ in radius and $25 \mathrm{~m}$ in length was horizontally stretched, away from the simulated lightning channel, at a height of $0.5 \mathrm{~m}$ above ground. The close (to the simulated

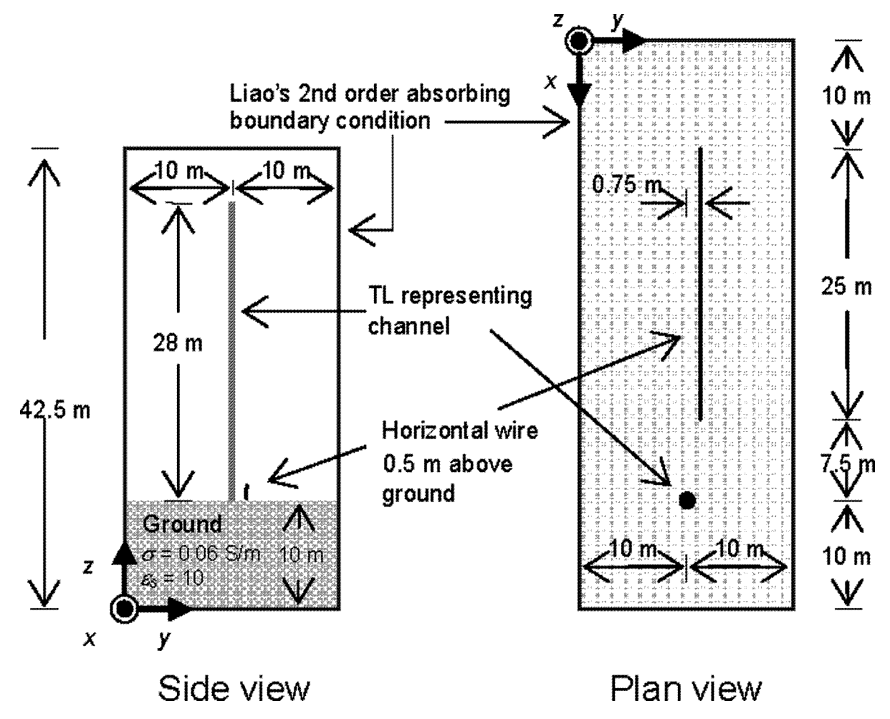

Fig. 13. A 25-m-long horizontal wire, one end of which is at distances $x=7.5 \mathrm{~m}$ and $y=0.75 \mathrm{~m}$ from a simulated lightning channel, as in Ishii et al.'s [27] small-scale experiment, simulated here using the FDTD method. The close (to the simulated channel) end of the horizontal wire is either terminated in a $430-\Omega$ resistance in parallel with a $20-\mathrm{pF}$ capacitance (representing the input capacitance of voltage probe) or in a $20-\mathrm{pF}$ capacitance, and the remote end is terminated in a $430-\Omega$ resistance in parallel with a $20-p F$ capacitance. The lightning channel is represented by a vertical array of current sources that are specified using the "engineering" TL model [37], and the return-stroke speed is set to $125 \mathrm{~m} / \mu$ s. The working volume of $52.5 \times 20 \times 42.5 \mathrm{~m}^{3}$, which is divided into $0.25 \times 0.25 \times 0.25 \mathrm{~m}^{3}$ cubic cells, is surrounded by six planes of Liao's secondorder absorbing boundary condition [28] in order to avoid reflections there.

channel) end of this horizontal wire was either terminated in a $430-\Omega$ resistor or left open, and the remote end was terminated in a $430-\Omega$ resistor. The lightning-induced voltages at both ends of the wire were measured using voltage probes having $20-\mathrm{pF}$ input capacitance.

Fig. 13 shows the configuration of Ishii et al.'s [27] smallscale experiment that we simulated using the FDTD method. We set the conductivity and relative permittivity of ground to $\sigma=0.06 \mathrm{~S} / \mathrm{m}$ and $\varepsilon_{r}=10$, respectively. Note that Ishii et al. [27] successfully reproduced lightning-induced voltages measured in their experiment with Agrawal et al.'s field-to-wire electromagnetic coupling model [15], and Pokharel et al. [39] reproduced them with NEC-2 [3], both assuming $\sigma=0.06 \mathrm{~S} / \mathrm{m}$ and $\varepsilon_{r}=10$. We represented the lightning return stroke channel by a vertical array of current sources [31] that were specified using the TL model [37] and set the return stroke speed to 125 $\mathrm{m} / \mu \mathrm{s}$. We represented the horizontal wire of radius $0.25 \mathrm{~mm}$ in the rectangular-geometry FDTD procedure by employing a method proposed by Noda and Yokoyama [29]. They found that a thin wire in air had an equivalent radius of $0.23 \Delta s$ ( $\Delta s$ is the side length of cubic cells used in FDTD simulations) in the case that the electric field along the axis of the thin wire was set to zero in an orthogonal and uniform Cartesian grid for FDTD simulations. They further showed that a thin wire having an arbitrary radius $r_{0}^{*}$ could be equivalently represented by placing a zero-radius wire in an artificial rectangular prism, coaxial with the thin wire, having a cross-sectional area of $2 \Delta s \times 2 \Delta \mathrm{s}$ and the modified relative permittivity and 


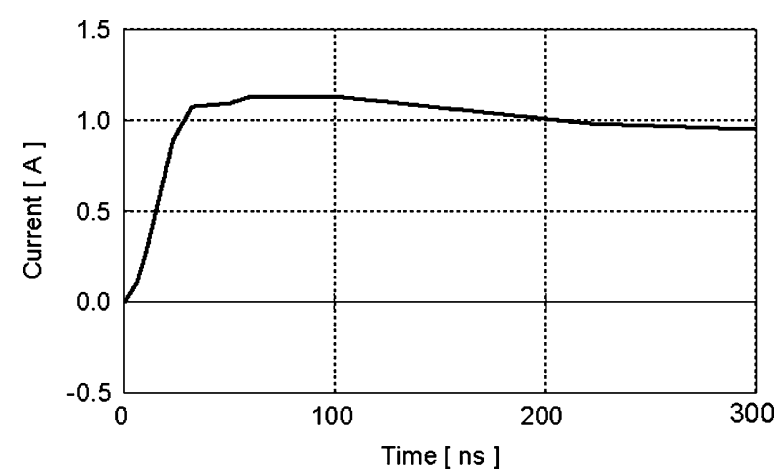

Fig. 14. Injected current waveform measured by Ishii et al. [27], which we used as the channel-base current waveform in the TL model. The TL modelpredicted distribution of current along the lightning channel was used in FDTD calculations of lightning-induced voltages on the horizontal wire.

permeability given by $\varepsilon_{r}^{*}=\ln (1 / 0.23) / \ln \left(\Delta s / r_{0}^{*}\right)$ and $\mu_{r}^{*}=$ $\ln \left(\Delta s / r_{0}^{*}\right) / \ln (1 / 0.23)$. In our calculations, since $\Delta s=0.25$ $\mathrm{m}$ and $r_{0}^{*}=0.25 \mathrm{~mm}$, we set $\varepsilon_{r}^{*}=0.213$ and $\mu_{r}^{*}=1 / 0.213=$ $4.69\left(\varepsilon_{r}^{*} \varepsilon_{0} \mu_{r}^{*} \mu_{0}=\varepsilon_{0} \mu_{0}=1 / c^{2}\right)$.

In order to test the validity of the FDTD method, we calculated lightning-induced voltages at both ends of the horizontal wire (Ishii et al. [27] measured induced voltages only at the ends of the horizontal wire) up to $300 \mathrm{~ns}$ with a time increment of $0.25 \mathrm{~ns}$.

Fig. 14 shows the injected current waveform measured by Ishii et al., which we used as the channel-base current waveform in the TL model. Fig. 15(a) shows induced-voltage waveforms at the close and remote ends of the horizontal wire calculated using the FDTD method and those measured by Ishii et al. [27] in the case of both ends being terminated in a parallel circuit of $430-\Omega$ resistance and $20-\mathrm{pF}$ capacitance. Fig. 15(b) shows those in the case of the close end being terminated in a $20-\mathrm{pF}$ capacitance and the remote end being terminated in a parallel circuit of $430-\Omega$ resistance and $20-\mathrm{pF}$ capacitance. It is clear from Fig. 15(a) and (b) that induced voltages calculated using the FDTD method agree reasonably well with those measured. Note that the FDTD-calculated voltage waveforms are also in good agreement with those calculated for the case of strikes to flat ground using Agrawal's field-to-wire coupling model [27] and those calculated using NEC-2 [39], although results for the latter two approaches are not presented in this paper. Hence, we conclude that our FDTD method yields reasonably accurate lightning-induced voltages on a horizontal wire above ground, at least for the case of strikes to flat ground.

\section{APPENDIX B}

\section{COMPARISON WITH RUSCK'S FORMULA (STRIKES TO FLAT GROUND)}

In this Appendix, we compare the magnitudes of lightninginduced voltages at the center point of a 1200 -m-long horizontal wire (matched at both ends) above perfectly conducting ground, calculated using the FDTD method, with those calculated using Rusck's formula [13]. Rusck derived the following expression

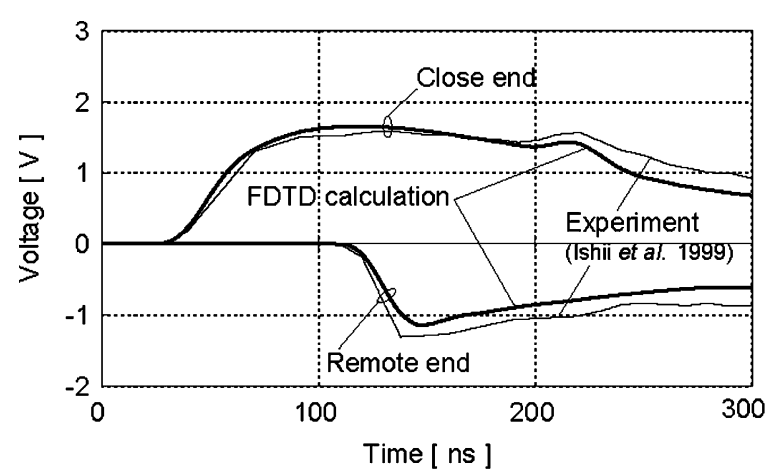

(a)

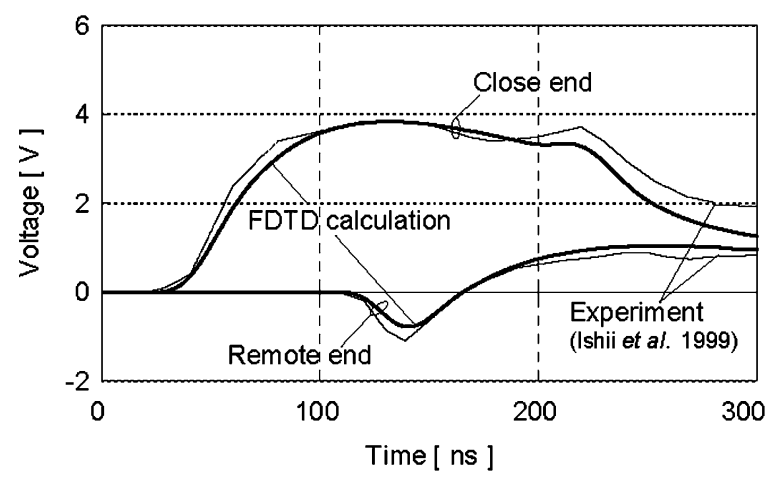

(b)

Fig. 15. Induced-voltage waveforms at the close and remote ends of the horizontal wire, calculated using the FDTD method, and those measured by Ishii et al. [27] (a) for the case of both ends of the horizontal wire being terminated in a $430-\Omega$ resistance in parallel with a $20-\mathrm{pF}$ capacitance and (b) for the case of the close end being terminated in a $20-\mathrm{pF}$ capacitance and the remote end in a $430-\Omega$ resistance in parallel with a $20-\mathrm{pF}$ capacitance.

for the magnitude of lightning-induced voltage $V_{\mathrm{R} \_f l a t}$ at the center point of an infinitely long horizontal wire at height $h_{l}$ above perfectly conducting ground for a return stroke current represented by a step function propagating at speed $v$ along the vertical lightning channel attached to flat ground.

$$
V_{\mathrm{R} \_f l a t}=\frac{30 I_{\max } h_{l}}{d}\left(1+\frac{1}{\sqrt{2}} \frac{v}{c} \frac{1}{\sqrt{1-(v / c)^{2} / 2}}\right)
$$

where $I_{\max }$ is the magnitude of the return stroke current, and $d$ is the horizontal distance from the lightning channel to the wire. Since we used a short-front current waveform rising from zero to its maximum in about $0.5 \mu \mathrm{s}$ (the corresponding 10-90\% RT is $0.15 \mu \mathrm{s}$ ) in calculating lightning-induced voltages shown in Fig. 2(b), we expect the magnitude of FDTD-calculated lightning-induced voltage [Fig. 2(b)] to be similar to that calculated using (B1). Table II shows the magnitudes of lightninginduced voltages calculated using the FDTD method and (B1) for the case of perfectly conducting ground $(\sigma=\infty)$. It is clear from Table II that the magnitudes of induced voltages calculated using these two methods are in good agreement. Note that the magnitudes of lightning-induced voltages for a ground having $\sigma=10 \mathrm{mS} / \mathrm{m}$ and $\varepsilon_{r}=10$ are $116,80.4,49.7$, and $25.2 \mathrm{kV}$ at distances $d=40,60,100$, and 200, respectively, which are only $8-24 \%$ higher than those for $\sigma=\infty$. 
TABLE II

Magnitudes of Lightning-INDUCED Voltages at THE CENTER Point OF A 1200-M-LONG HORIZONTAL WIRE 10 M ABOVE PERFECTLY CONDUCTING GROUND*

\begin{tabular}{c|c|c|c}
\hline \multirow{2}{*}{$d[\mathrm{~m}]$} & \multicolumn{2}{|c|}{ Induced voltage [ kV ] } & \multirow{2}{*}{} \\
\cline { 2 - 3 } & FDTD & Rusck & Difference [\%] \\
\hline 40 & 107 & 102 & 4.9 \\
60 & 71.6 & 68.0 & 5.3 \\
100 & 42.4 & 40.8 & 3.9 \\
200 & 20.4 & 20.4 & 0.0 \\
\hline
\end{tabular}

*Calculated using the FDTD method for a lightning strike to flat ground and those

calculated using Rusck's formula [13]. The latter is an approximate formula that is derived for a step-function current wave, while the FDTD calculation uses a current waveform thought to be typical for lightning subsequent return strokes. The magnitude of return stroke current is assumed to be $11 \mathrm{kA}$ and the return stroke speed is set to $d 3$.

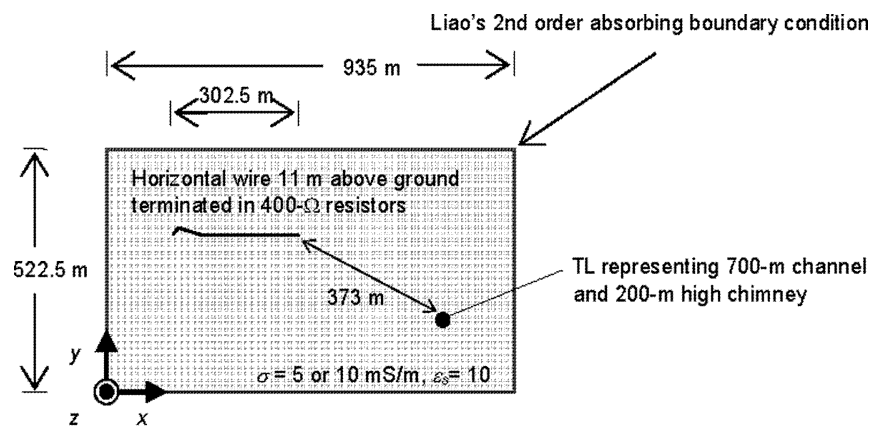

Plan view

Fig. 16. About 300-m-long horizontal wire, each end of which is terminated in a $400-\Omega$ resistor, as in the Michishita et al. [23] field experiment, whose interaction with lightning striking the 200-m-high Fukui chimney is simulated using the FDTD method. Both the lightning channel and the 200-m-high strike object are represented by the TL model extended to include a tall object [5]. The working volume of $935 \times 522.5 \times 1045 \mathrm{~m}^{3}$, which is divided into $5.5 \times 5.5 \times 5.5 \mathrm{~m}^{3} \mathrm{cu}-$ bic cells, is surrounded by six planes of Liao's second-order absorbing boundary condition [28] in order to avoid reflections there. The conductivity and relative permittivity of ground are set to $\sigma=5$ or $10 \mathrm{mS} / \mathrm{m}$ and $\varepsilon_{r}=10$, respectively.

\section{APPENDIX C}

\section{TESTING THE VALIDITY OF THE FDTD CALCULATIONS AGAINST EXPERIMENTAL DATA (STRIKES TO A TALl OBJECT)}

Michishita et al. [23] measured lightning-induced voltages on an overhead test distribution line simultaneously with lightning currents at the top of a 200-m-high strike object (Fukui chimney). Fig. 16 shows the configuration of their experiment that we simulated using the FDTD method. A horizontal wire $2.5 \mathrm{~mm}$ in radius and about $300 \mathrm{~m}$ in length was stretched $11 \mathrm{~m}$ above ground. Both ends of this horizontal wire were terminated in 400- $\Omega$ resistors. Lightning-induced voltages at each end of the horizontal wire were measured. Michishita et al. [23] reasonably well reproduced their measured lightning-induced voltages using the Agrawal model [15]. They represented the strike object by a lossless uniform transmission line with characteristic impedance $Z_{\text {ob }}=250 \Omega$, terminated in a $100-\Omega$ resistance in parallel with a $10-\Omega$ resistance and a $0.3 \mathrm{mH}$ inductance (corresponding $\rho_{\text {bot }}=0.42,0.45$, and 0.52 for frequencies equal to infinity, 1 , and $0.2 \mathrm{MHz}$, respectively). Lightning channel was represented by a lossless uniform transmission line

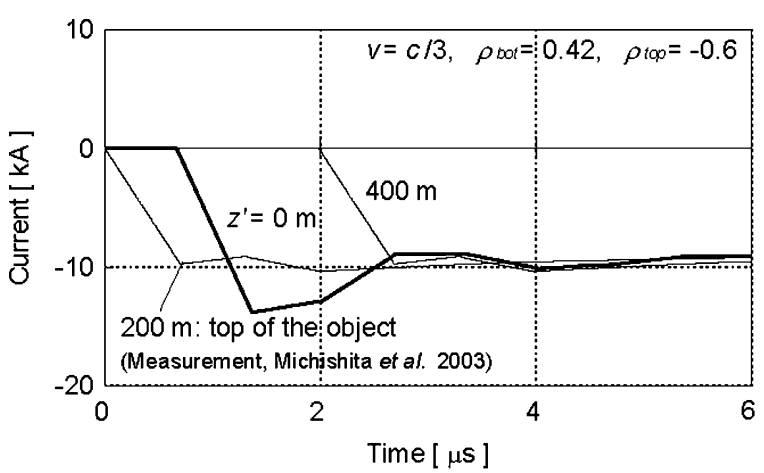

(a)

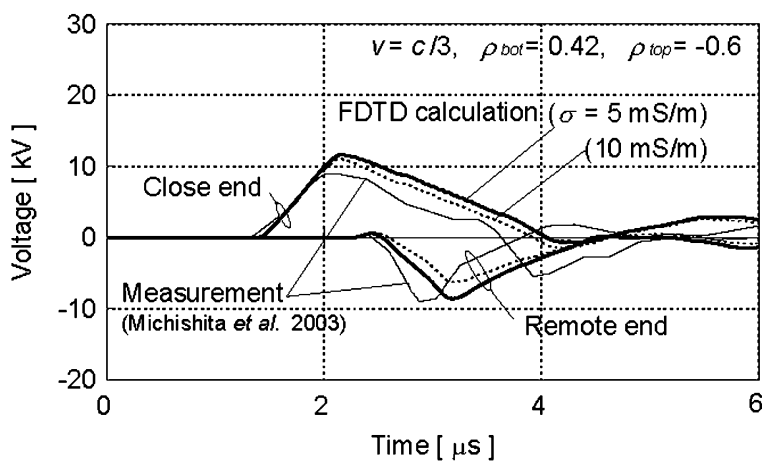

(b)

Fig. 17. (a) Current waveform measured at the top of the 200-m-high object [23], which was used as $I(h, t)$ in (2a) and (2b), and current waveforms at $z^{\prime}=0$ (bottom of the object) and $400 \mathrm{~m}$ (200 $\mathrm{m}$ above the top of the object), calculated using (2a) and (2b) for $v=c / 3, \rho_{\text {top }}=-0.6$ and $\rho_{\text {bot }}=0.42$. (b) Induced voltage waveforms measured at the close (to the simulated channel) and remote ends of the horizontal wire by Michishita et al. [23] and those calculated using the FDTD method.

whose characteristic impedance $Z_{\mathrm{ch}}=1000 \Omega$ (corresponding to $\left.\rho_{\text {top }}=-0.6\right)$ and the current-propagation speed along the channel was set to $v=c / 3$. The conductivity and relative permittivity of ground were set to $\sigma=10 \mathrm{mS} / \mathrm{m}($ or $\infty)$ and $\varepsilon_{r}=10$, respectively.

We used the TL model extended to include a tall strike object to represent the Fukui chimney and the lightning channel. Following Michishita et al. [23], we set $\rho_{\text {top }}=-0.6, \rho_{\text {bot }}=0.42$, and $v=c / 3$. The current distribution along the object and channel is given by (2a) and ( $2 b)$, respectively. The conductivity and relative permittivity of ground were set to $\sigma=5$ or $10 \mathrm{mS} / \mathrm{m}$ and $\varepsilon_{r}=10$, respectively. One of the values of conductivity $(10 \mathrm{mS} / \mathrm{m})$ was used by Michishita et al. [23], and the other $(5 \mathrm{mS} / \mathrm{m})$ was additionally selected because it provided a better agreement between model-predicted and measured voltages at the remote end of the wire. The overhead horizontal wire, a portion of which near the remote end was neither parallel nor perpendicular to $x$ - or $y$-axis (see Fig. 16), was simulated using a staircase approximation in the FDTD calculations. Lightning-induced voltages at each end of the horizontal wire were calculated up to $6 \mu$ s with a time increment of $5 \mathrm{~ns}$.

Fig. 17(a) shows the current waveform measured by Michishita et al. at the top of the Fukui chimney, which was employed as $I(h, t)$ in (2a) and (2b). Current waveforms at $z^{\prime}=0$ (bottom of the Fukui chimney) and $z^{\prime}=400 \mathrm{~m}$ 
(200 $\mathrm{m}$ above the top of the Fukui chimney) calculated for $\rho_{\text {top }}=-0.6, \rho_{\text {bot }}=0.42$, and $v=c / 3$ are also shown in Fig. 17(a). Fig. 17(b) shows induced-voltage waveforms at the close and remote ends of the horizontal wire, calculated using the FDTD method for two different values of ground conductivity, along with those measured by Michishita et al. [23]. It is clear from Fig. 17(b) that induced voltages calculated using the FDTD method are in good agreement with measured ones. Hence, we conclude that our FDTD method yields reasonably accurate lightning-induced voltages on a horizontal wire above ground for the case of strikes to a tall object.

\section{ACKNOWLEDGMENT}

The authors would like to thank F. Rachidi, S. F. Visacro, and three anonymous reviewers for their valuable comments on the paper.

\section{REFERENCES}

[1] R. J. Fisher and G. H. Schnetzer, "1993 Triggered Lightning Test Program: Environments Within 20 Meters of the Lightning Channel and Small Area Temporary Protection Concepts," Sandia Nat. Lab., Sandia, NM, Sandia Rep., SAND94-0311/UC-706, 1994.

[2] S. Miyazaki and M. Ishii, "Influence of elevated stricken object on lightning return-stroke current and associated fields," in Proc. 27th Int. Conf. Lightning Protection, Avignon, France, Sep. 2004, pp. 122-127.

[3] G. J. Burke and A. J. Poggio, "Numerical electromagnetic code (NEC)Method of moments,"Naval Ocean Systems Center, San Diego, CA, Tech. Document 116, 1980.

[4] Y. Baba and V. A. Rakov, "Lightning electromagnetic environment in the presence of a tall grounded strike object," J. Geophys. Res., vol. 110, D09108, doi:10.1029/ 2004JD005505, total numbers of pages 10, May 2005.

[5] - "On the use of lumped sources in lightning return stroke models," J. Geophys. Res., vol. 110, D03101 doi: 10.1029/2004JD005202, total numberd of pages 18, Feb. 2005.

[6] G. Diendorfer and W. Schulz, "Lightning incidence to elevated objects on mountains," in Proc. 24th Int. Conf. Lightning Protection, Birmingham, U.K., 1998, pp. 173-175.

[7] F. Rachidi, W. Janischewskyj, A. M. Hussein, C. A. Nucci, S. Guerrieri, B. Kordi, and J.-C. Chang, "Current and electromagnetic field associated with lightning-return strokes to tall towers," IEEE Trans. Electromagn. Compat., vol. 43, no. 3, pp. 356-367, Aug. 2001

[8] V. A. Rakov, "Transient response of a tall object to lightning," IEEE Trans. Electromagn. Compat., vol. 43, no. 4, pp. 654-661, Nov. 2001.

[9] B. Kordi, R. Moini, W. Janischewskyj, A. M. Hussein, V. O. Shostak, and V. A. Rakov, "Application of the antenna theory model to a tall tower struck by lightning," J. Geophys. Res., vol. 108, no. D17, DOI: 10.1029/2003JD003398, 2003.

[10] J. L. Bermudez, F. Rachidi, M. Rubinstein, W. Janischewskyj, V. Shostak, D. Pavanello, J. S. Chang, A. M. Hussein, C. A. Nucci, and M. Paolone, "Far-field-current relationship based on the TL model for lightning return strokes to elevated strike objects," IEEE Trans. Electromagn. Compat., vol. 47, no. 1, pp. 146-159, Feb. 2005.

[11] A. Piantini and J. M. Janiszewski, "Induced voltages on distribution lines due to lightning discharges on nearby metallic structures," IEEE Trans. Magn., vol. 34, no. 5, pp. 2799-2802, Sep. 1998.

[12] - "The extended Rusck model for calculating lightning induced voltages on overhead lines," in Proc. VII Int. Symp. Lightning Protection, Curitiba, Brazil, Nov. 2003, pp. 151-155.

[13] S. Rusck, "Induced over-voltages on power-transmission lines with special reference to the over-voltage protection of low-voltage networks," Trans. Royal Inst. Tech., Stockholm, Sweden, no. 120, pp. 1-118, 1958.

[14] V. Cooray, "Calculating lightning-induced overvoltages in power lines: A comparison of two coupling models," IEEE Trans. Electromagn. Compat., vol. 36, no. 3, pp. 179-182, Aug. 1994.

[15] A. K. Agrawal, H. J. Price, and S. H. Gurbaxani, "Transient response of multiconductor transmission lines excited by a nonuniform electromagnetic field," IEEE Trans. Electromagn. Compat., vol. EMC-22, no. 2, pp. 119-129, May 1980.
[16] K. Michishita and M. Ishii, "Theoretical comparison of Agrawal's and Rusck's field-to-line coupling models for calculation of lightning-induced voltage on an overhead wire," IEEJ Trans. PE, vol. 117, no. 9, pp. 13151316, Sep. 1997.

[17] S. Yokoyama, K. Miyake, H. Mitani, and A. Takanishi, "Simultaneous measurement of lightning induced voltages with associated stroke currents," IEEE Trans. Power App. Syst., vol. PAS-102, no. 8, pp. 2420-2429, Aug. 1983.

[18] S. Yokoyama, K. Miyake, H. Mitani, and N. Yamazaki, "Advanced observation of lightning induced voltage on power distribution line," IEEE Trans. Power Del., vol. PD-1, no. 2, pp. 129-139, Apr. 1986.

[19] F. Rachidi, "Formulation of the field-to-transmission line coupling equations in terms of magnetic excitation field," IEEE Trans. Electromagn. Compat., vol. 35, no. 3, pp. 404-407, Aug. 1993.

[20] F. H. Silveira and S. F. Visacro, "Lightning induced overvoltages: The influence of lightning and line parameters," in Proc. Int. Conf. Grounding and Earthing \& 3rd Brazilian Workshop on Atmospheric Electricity, Rio de Janeiro, Brazil, Nov. 2002, pp. 105-110.

[21] F. H. Silveira, C. R. Mesquita, and S. Visacro, "Evaluation of the influence of lightning channel and return current characteristics on induced overvoltages," presented at the 26th Int. Conf. Lightning Protection, Cracow, Poland, 2002.

[22] S. Visacro, A. J. Soares, and M. A. O. Schroeder, "An interactive computational code for simulation of transient behavior of electric system components for lightning currents," presented at the 26th Int. Conf. Lightning Protection, Cracow, Poland, 2002.

[23] K. Michishita, M. Ishii, A. Asakawa, S. Yokoyama, and K. Kami, "Voltage induced on a test distribution line by negative winter lightning strokes to a tall structure,"IEEE Trans. Electromagn. Compat., vol. 45, no. 1, pp. 135140, Feb. 2003.

[24] R. K. Pokharel, Y. Baba, and M. Ishii, "Numerical electromagnetic field analysis of transient induced voltages associated with lightning to a tall structure," J. Electrostatics, vol. 60, no. 2-4, pp. 141-147, Mar. 2004.

[25] K. A. Norton, "The propagation of radio waves over the surface of the earth and in the upper atmosphere," Proc. IRE, vol. 25, no. 9, pp. 1203-1236, 1937.

[26] K. S. Yee, "Numerical solution of initial boundary value problems involving Maxwell's equation in isotropic media," IEEE Trans. Antennas Propagat., vol. 14, no. 3, pp. 302-307, Mar. 1966.

[27] M. Ishii, K. Michishita, and Y. Hongo, "Experimental study of lightninginduced voltage on an overhead wire over lossy ground," IEEE Trans. Electromagn. Compat., vol. 41, no. 1, pp. 39-45, Feb. 1999.

[28] Z. P. Liao, H. L. Wong, B.-P. Yang, and Y.-F. Yuan, "A transmitting boundary for transient wave analysis," Science Sinica, vol. A27, no. 10, pp. 1063-1076, 1984.

[29] T. Noda and S. Yokoyama, "Thin wire representation in finite difference time domain surge simulation," IEEE Trans. Power Del., vol. 17, no. 3, pp. 840-847, Jul. 2002.

[30] V. A. Rakov and M. A. Uman, "Review and evaluation of lightning return stroke models including some aspects of their application," IEEE Trans. Electromagn. Compat., vol. 40, no. 4, pp. 403-426, Nov. 1998.

[31] Y. Baba and V. A. Rakov, "On the transmission line model for lightning return stroke representation," Geophys. Res. Lett., vol. 30, no. 24, 2294, DOI: 10.1029/2003GL018407, Dec. 2003.

[32] V. A. Rakov, "Lightning return stroke speed: A review of experimental data," in Proc. 27th Int. Conf. Lightning Protection, Avignon, France, Sep. 2004, pp. 139-144.

[33] W. Janischewskyj, V. Shostak, J. Barratt, A. M. Hussein, R. Rusan, and J.-S. Chang, "Collection and use of lightning return stroke parameters taking into account characteristics of the struck object," in Proc. 23rd Int. Conf. Lightning Protection, Florence, Italy, 1996, pp. 16-23.

[34] F. Fuchs, "On the transient behaviour of the telecommunication tower at the mountain Hoher Peissenberg," in Proc. 24th Int. Conf. Lightning Protection, vol. 1, Birmingham, U.K., 1998, pp. 36-41.

[35] V. A. Rakov, M. A. Uman, K. J. Rambo, M. I. Fernandez, R. J. Fisher G. H. Schnetzer, R. Thottappillil, A. Eybert-Berard, J. P. Berlandis, P. Lalande, A. Bonamy, P. Laroche, and A. Bondiou-Clergerie, "New insights into lightning processes gained from triggered-lightning experiments in Florida and Alabama," J. Geophys. Res., vol. 103, no. D12, pp. 14117 14139, 1998.

[36] C. A. Nucci, G. Diendorfer, M. A. Uman, F. Rachidi, M. Ianoz, and C. Mazzetti, "Lightning return stroke current models with specified channel-base current: A review and comparison," J. Geophys. Res., vol. 95 , no. D12, pp. 20395-20408, 1990. 
[37] M. A. Uman and D. K. McLain, "The magnetic field of the lightning return stroke," J. Geophys. Res., vol. 74, pp. 6899-6910, 1969.

[38] C. F. Wagner and G. D. McCann, "Induced voltages on transmission lines," AIEE Trans., vol. 61, pp. 916-930, 1942.

[39] R. K. Pokharel, M. Ishii, and Y. Baba, "Numerical electromagnetic analysis of lightning-induced voltage over ground of finite conductivity," IEEE Trans. Electromagn. Compat., vol. 45, no. 4, pp. 651-666, Nov. 2003.

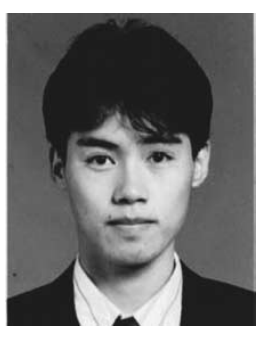

Yoshihiro Baba (S'95-M'99) received the B.S., M.S., and Dr. Eng. degrees in electrical engineering from the University of Tokyo, Tokyo, Japan, in 1994, 1996, and 1999, respectively.

From April 2003 to August 2004, he was a Visiting Scholar at the University of Florida, Gainesville, on sabbatical leave from Doshisha University, Kyoto, Japan. He is currently an Associate Professor at the Department of Electrical Engineering, Doshisha University. He is the author or coauthor of over 20 papers published in reviewed journals.

Dr. Baba is a member of AGU and IEE.

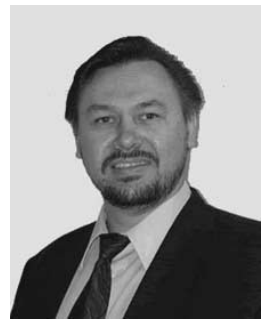

Vladimir A. Rakov (SM'96-F'03) received the M.S and Ph.D. degrees in electrical engieering from the Tomsk Polytechnical University (Tomsk Polytechnic), Tomsk, Russia, in 1977 and 1983, respectively.

From 1977 to 1979, he worked as an Assistant Professor of electrical engineering at Tomsk Polytechnic. In 1978, he became involved in lightning research at the High Voltage Research Institute (a division of Tomsk Polytechnic), where from 1984 to 1994, he held the position of the Director of the Lightning Research Laboratory. He is currently a Professor at the Department of Electrical and Computer Engineering, University of Florida, Gainesville, and Co-Director of the International Center for Lightning Research and Testing (ICLRT). He is the author of one book, over 30 patents, and over 300 papers and technical reports on various aspects of lightning, with over 120 papers being published in reviewed journals.

Dr. Rakov is the Chairman of the Technical Committee on Lightning of the Biennial International Zurich Symposium on Electromagnetic Compatibility and former Chairman of the AGU Committee on Atmospheric and Space Electricity (CASE). He is a fellow of AMS and IEE and a member of AGU, SAE, and ASEE. 